\title{
Retrograde BMP Signaling at the Synapse: A Permissive Signal for Synapse Maturation and Activity-Dependent Plasticity
}

\author{
Brett Berke, ${ }^{1}$ Jessica Wittnam, ${ }^{1}$ Elizabeth McNeill, ${ }^{2}$ David L. Van Vactor, ${ }^{2}$ and Haig Keshishian ${ }^{1}$ \\ ${ }^{1}$ Molecular, Cellular, and Developmental Biology Department, Yale University, New Haven, Connecticut 06520, and ${ }^{2}$ Department of Cell Biology, Harvard \\ Medical School, Boston, Massachusetts 02115
}

At the Drosophila neuromuscular junction (NMJ), the loss of retrograde, trans-synaptic BMP signaling causes motoneuron terminals to have fewer synaptic boutons, whereas increased neuronal activity results in a larger synapse with more boutons. Here, we show that an early and transient BMP signal is necessary and sufficient for NMJ growth as well as for activity-dependent synaptic plasticity. This early critical period was revealed by the temporally controlled suppression of Mad, the SMAD1 transcriptional regulator. Similar results were found by genetic rescue tests involving the BMP4/5/6 ligand Glass bottom boat $(\mathrm{Gbb})$ in muscle, and alternatively the type II BMP receptor Wishful Thinking (Wit) in the motoneuron. These observations support a model where the muscle signals back to the innervating motoneuron's nucleus to activate presynaptic programs necessary for synaptic growth and activity-dependent plasticity. Molecular genetic gain- and loss-of-function studies show that genes involved in NMJ growth and plasticity, including the adenylyl cyclase Rutabaga, the Ig-CAM Fasciclin II, the transcription factor AP-1 (Fos/Jun), and the adhesion protein Neurexin, all depend critically on the canonical BMP pathway for their effects. By contrast, elevated expression of Lar, a receptor protein tyrosine phosphatase found to be necessary for activity-dependent plasticity, rescued the phenotypes associated with the loss of Mad signaling. We also find that synaptic structure and function develop using genetically separable, BMP-dependent mechanisms. Although synaptic growth depended on Lar and the early, transient BMP signal, the maturation of neurotransmitter release was independent of Lar and required later, ongoing BMP signaling.

\section{Introduction}

Growth factors released from postsynaptic target cells can act in a retrograde fashion to influence the development and function of presynaptic terminals (Poo, 2001; Hensch, 2004). Bone morphogenetic proteins (BMPs) are retrograde, trans-synaptic signals that are widely expressed within the developing nervous system (Zhang et al., 1998; Augsburger et al., 1999; Ming et al., 2002) and affect presynaptic growth and neurotransmission both centrally and at neuromuscular junctions (NMJ) (Baines, 2004; Marqués, 2005; Xiao et al., 2013). For example, Drosophila mutations affecting BMP signaling suppress the dramatic increase in NMJ size and strength that normally occurs over $4 \mathrm{~d}$ of development

Received Dec. 7, 2011; revised 0ct. 4, 2013; accepted 0ct. 8, 2013.

Author contributions: B.A.B., D.L.V.V., and H.K. designed research; B.A.B., J.W., and E.M. performed research; B.A.B. contributed unpublished reagents/analytic tools; B.A.B., E.M., and H.K. analyzed data; B.A.B., E.M., D.L.V.V., and H.K. wrote the paper.

This work was supported by the National Institutes of Health Grants 5R01NS031651 and 1R21NS053807 to H.K., the National Science Foundation (IBN 0641915), and National Institute of Neurological Disorders and Stroke Grant P01 NS066888 to D.L.V.V. We thank M. O'Connor, M. Bhat, S. Sanyal, K. Wharton, S. Selleck, D. Allen, K. O'ConnorGiles, P. ten Dijke, G. Marqués, and the Bloomington Stock Center for generously providing Drosophila stocks, reagents, and protocols; and R. Wyman, W. Zhong, M. Garcia-Castro, and members of the H.K. and D.L.V.V. laboratories for their advice and comments on the manuscript.

The authors declare no competing financial interests.

Correspondence should be addressed to Dr. Haig Keshishian, Molecular, Cellular, and Developmental Biology Department, Yale University, POB 208103, New Haven, Connecticut 06520. E-mail: haig.keshishian@yale.edu.

DOI:10.1523/JNEUROSCI.6075-11.2013

Copyright $\odot 2013$ the authors $\quad 0270-6474 / 13 / 3317937-14 \$ 15.00 / 0$
(Keshishian et al., 1993; Zito et al., 1999; Aberle et al., 2002; Marqués et al., 2002; McCabe et al., 2003; Rawson et al., 2003; Eaton and Davis, 2005; Goold and Davis, 2007). However, we do not yet know when BMP signaling exerts its effects. Does BMP signaling permit synapse maturation before the robust growth of the NMJ or does it direct synapse development in an on-going manner depending on the level of synaptic drive?

Two downstream BMP effectors have distinct roles in the structural and functional development of the NMJ (Ball et al., 2010; Kim and Marqués, 2012). Expression of the guaninenucleotide exchange factor Trio partially rescues synaptic growth in BMP pathway mutants, without rescue of synaptic physiology (Ball et al., 2010). By contrast, Twit, a Ly6 neurotoxin-like molecule, partially rescues spontaneous neurotransmission with no rescue of NMJ growth (Kim and Marqués, 2012). These observations suggest that distinct sets of effectors may regulate NMJ growth and function. Some of these players might include mechanisms of activity-dependent NMJ plasticity, such as cAMP signaling, the transcriptional regulators $\mathrm{AP}-1$ and $\mathrm{CREB}$, or adhesion molecules, such as the IgCAM Fasciclin-2 (Fas-2) and Neurexin (Ganetzky and Wu, 1983; Budnik et al., 1990; Zhong et al., 1992; Davis et al., 1996; Schuster et al., 1996b; Davis and Goodman, 1998; Cheung et al., 1999; Shayan and Atwood, 2000; Sanyal et al., 2002; Sigrist et al., 2003; Zhong and Wu, 2004; Ashley et al., 2005). However, a role for BMP signaling in synaptic 
plasticity and its affects on these molecular systems remain largely uncharacterized.

Here, we show that NMJ growth and its modulation by activity require an early and transient BMP signal before the robust expansion of the NMJ, whereas retrograde control of NMJ function starts early and requires continuous BMP signaling throughout development. We also find that the receptor protein tyrosine phosphatase Lar, a molecule that regulates NMJ size, rescues the structural changes associated with BMP loss of function and the ability to grow in response to increased activity but does not rescue the physiological phenotypes. Our observations therefore indicate that two genetically separable BMP-dependent mechanisms regulate NMJ structure and function, both of which are initiated by a permissive "go" signal sent to the innervating neuron's nucleus.

\section{Materials and Methods}

Drosophila stocks. All stocks were raised at $22^{\circ} \mathrm{C}$ with Canton $\mathrm{S}$ as the wild-type (WT). The following null or strong hypomorphic alleles used in this study include the following: $w_{i t}^{A 12}$, wit ${ }^{B 11}$, wit ${ }^{G 15}, g b b^{1}, g b b^{2}$, $\mathrm{mad}^{1}$, and $\mathrm{mad}^{12}$ from K. Wharton (Brown University, Providence, RI), M. O'Connor and S. Selleck (University of Minnesota, Minneapolis, $\mathrm{MN}$ ), and the Bloomington Stock Center (Bloomington, IN). The deficiency $D f(3) L C 175$ st (from M. O'Connor) spans the wit gene and was used to verify a role for Wit in NMJ plasticity. Gain-of-function experiments were performed by the presynaptic expression of constitutively active type I BMP/TGF- $\beta$ receptors ( $y w$; UAS-tkv ${ }^{A C T}$ and $y w$; UAS$s a x^{A C T}$; from D. Allen, University of British Columbia, Vancouver, British Columbia, Canada). The activity of $\mathrm{Tkv}^{\mathrm{ACT}}$ and $\mathrm{Sax}^{\mathrm{ACT}}$ was verified by expressing each in developing wing discs (using the $w$, A9-GAL4 driver from K. O'Connor-Giles, University of Wisconsin, Madison, WI), which resulted in wing expansion defects as previously described for BMP gainof-function manipulations (Haerry et al., 1998). Transgenes were expressed pan-neuronally using mifepristone (RU-486)-inducible GeneSwitch (GS) GAL4 drivers that express transgenes in all neurons (ELAV-GS-GAL4) and the body wall musculature (MHC-GS-GAL4) (Osterwalder et al., 2001). The TARGET temperature-conditional expression system (McGuire et al., 2003, 2004) was used to rescue wit mutations pan-neuronally with the ELAV $V^{C 155}$-GAL4 driver expressing Wit transgenes (UAS-Wit-GFP and UAS-WitATFlag1x, from $\mathrm{M}$. O'Connor, University of Minnesota, Minneapolis, MN).

Neuronal excitability was elevated by either crossing in the $\mathrm{K}^{+}$channel mutations eag ${ }^{1} \mathrm{Sh}^{120}$ (Budnik et al., 1990) or by rearing animals at $30^{\circ} \mathrm{C}$ (Peng et al., 2007). Both of these manipulations increase TTXsensitive spontaneous activity, stimulate NMJ growth, increase the complexity of synaptic arborizations, and rely on cAMP signaling for their effects on growth (Sigrist et al., 2003; Zhong and Wu, 2004; Peng et al., 2007). An intermediate elevation in activity was achieved using a null $S h$ mutation $\left(S h^{M}\right)$ or by rearing larvae at $25^{\circ} \mathrm{C}$ (Zhong and $\left.\mathrm{Wu}, 2004\right)$. For the $\mathrm{Mad}^{1}$ rescue experiments, we used UAS-dnrxf1, w (from M. Bhat, University of North Carolina, Chapel Hill, NC), w; UAS-Fos; UAS-Jun (from S. Sanyal, Emory University, Atlanta, GA), and w; UAS-Rut ${ }^{+}$ (from the Bloomington Stock Center, Bloomington, IN). The Lar ${ }^{13.2}$ / CyO-GFP, Lar ${ }^{5.5} F R T / C y O-G F P, w ; P\left[w^{+m c}=U A S . L a r . K\right] P 4 B$, and $y w ; ;$ $P^{+} 29\left[w^{+}\right.$, UAS-Lar-C1638S + C1929S $]$stocks were from D.V.V. and the Bloomington Stock Center.

UAS-Mad ${ }^{1}$ as a dominant-negative effector. The UAS-Mad ${ }^{1}$ transgene is derived from the $\mathrm{Mad}^{1}$ dominant allele. It encodes a mutant protein resulting from a base pair substitution in the conserved MH1 DNAbinding sequence of Mad while retaining the sites required for phosphorylation-dependent regulation and for binding to the co-SMAD Medea (Takaesu et al., 2005). Expression of $\mathrm{Mad}^{1}$ shows dominantnegative phenotypes during wing and peptidergic neuron development (Takaesu et al., 2005; Eade and Allan, 2009). The dominant-negative activity is likely to result from binding the co-SMAD Medea without being able to promote transcription, thus competing with WT Mad for its most common binding partner. In the embryonic and first larval instar
CNS, expression of the neuropeptide FMRFamide (FMRFa) is regulated by Mad, as wit mutations or $\mathrm{Mad}^{1}$ expression effectively suppress FMRFa transcription (D. Allan, personal communication; Allan et al., 2003; Eade and Allan, 2009). To assess how effectively Mad ${ }^{1}$ suppressed transcription during NMJ growth, we expressed $\mathrm{Mad}^{1}$ pan-neuronally with the ELAV-GS-GAL4 driver and measured FMRFa transcript in third instar larval brain using qPCR. Mad ${ }^{1}$ again reduced FMRFa levels to those of wit mutations: wit $\left(\right.$ wit $^{A 12} /$ wit $\left.^{B 11}\right)$ and $\mathrm{Mad}^{1}$ reduced transcript levels $\sim 3.5$-fold (WT, 0.00402; wit, 0.00112, $p=0.005$; $\mathrm{Mad}^{1}{ }^{1}$ without RU-486 induction, 0.00967; $\mathrm{Mad}^{1}$ with RU-486 induction 0.00275, $p=0.003$ ).

Presynaptic expression of $\mathrm{Mad}^{1}$ phenocopies the synaptic growth and most of the physiological defects observed in mad mutants (Rawson et al., 2003; McCabe et al., 2004) (see Figs. 1 and 9). The physiological phenotypes are likely due to ultrastructural defects in the synaptic release machinery, which in wit mutants include a decrease in the number and increase in size of active zones (Aberle et al., 2002; Marqués et al., 2002). We found that presynaptic Mad $^{1}$ expression similarly reduced the number but also aberrantly increased the size of active zones, as scored by immunolabeling of the active zone-associated protein Bruchpilot (Brp) (see Fig. 10). These results show that the expression of $\mathrm{Mad}^{1}$ faithfully recapitulated the phenotypes associated with various BMP signaling mutations.

Staging larval development and the temporal control of transgene expression. Newly deposited eggs were collected during $2 \mathrm{~h}$ time-windows at $25^{\circ} \mathrm{C}$ to obtain larvae at specific developmental stages. Larval development was further synchronized by collecting hatchling first instar (L1) larvae every $2 \mathrm{~h}$. Spiracle appearance, body size, and time were used to identify early second instar (L2) and third instar (L3) animals. For experiments using GS drivers, larvae and adults were cultured on media containing $5 \mu \mathrm{g} / \mathrm{ml}$ of the RU-486 steroid (Sigma), whereas control animals were raised on media lacking RU-486. Transgene expression in embryos was induced by exposing the parental flies to RU- 486 media for $4 \mathrm{~d}$ before egg collection. Some experiments included a yeast paste containing 50 $\mu \mathrm{g} / \mathrm{ml} \mathrm{RU}-486$ to ensure strong induction. To induce expression at specific developmental stages, larvae were raised on agarose plates containing yeast paste either with or without $50 \mu \mathrm{g} / \mathrm{ml} \mathrm{RU}-486$ and then transferred to normal or RU-486 containing food vials for the remainder of development. No significant difference in larval locomotion, size, or NMJ morphology was observed between animals grown in food vials versus yeast-containing agarose plates.

ELAV-GS-GAL4 induces detectable expression of GFP in the larval CNS some $5 \mathrm{~h}$ after exposure to RU-486 in food, with maximal expression after $12 \mathrm{~h}$, as determined by Western blot (Osterwalder et al., 2001). The onset of transgene expression contrasts with a slower time course for the loss of expression, likely because of transgene perdurance and the clearance of RU-486. We used the TARGET system of temperaturecontrolled transgene expression to control Wit expression (McGuire et al., 2003, 2004). Animals were maintained at either $18^{\circ} \mathrm{C}$ to suppress Wit expression or at $30^{\circ} \mathrm{C}$ to induce expression (through the relief of GAL $80^{\text {ts }}$-mediated inhibition of GAL4). Larval development is faster at $30^{\circ} \mathrm{C}$ than at $18^{\circ} \mathrm{C}$, so we monitored both spiracle shape and body size to accurately confirm developmental stages in synchronized larval populations. The onset and termination of transgene expression with TARGET may be faster than with GS as there is no time involved for ingestion and clearance of the steroid-inducing agent. Although transgene expression kinetics may be faster with TARGET, there is a robust temperature dependence of locomotion and NMJ activity, with high temperature increasing the size of the NMJ (Sigrist et al., 2003; Zhong and Wu, 2004). We took advantage of this effect to examine activity-dependent synaptic plasticity in wit mutants during the presence of an induced transgene.

Immunolabeling. Crawling third instar larvae were filleted in low $\mathrm{Ca}^{2+}$ (1 mm) saline, as previously described (Osterwalder et al., 2001), and fixed in $4 \%$ PFA (60 min at room temperature). All antibodies were prepared in a solution of $1 \%$ BSA diluted in PBS with Triton X-100 detergent (TBS: $20 \mathrm{~mm} \mathrm{NaH}_{2} \mathrm{PO}_{4}, 150 \mathrm{~mm} \mathrm{NaCl}, 0.3 \%$ Triton X-100, adjusted to $\mathrm{pH}$ 7.3). Tissues were incubated with agitation on an orbital shaker. NMJs were labeled with goat anti-HRP antibody overnight at $4^{\circ} \mathrm{C}$ (1:200, Cappel Laboratories), washed in TBS for $1 \mathrm{~h}$, and then stained with peroxidase-conjugated donkey anti-goat IgG for $2-4 \mathrm{~h}$ at room 
temperature (1:200, Jackson ImmunoResearch Laboratories). NMJs were visualized with $0.05 \% \mathrm{DAB}$ (Polysciences) in the presence of $0.003 \% \mathrm{H}_{2} \mathrm{O}_{2}$. The antibody specific to phosphorylated Mad was diluted 1:200 (pMad, PS1, rabbit; a gift from P. ten Dijke, University of Leiden, Leiden, The Netherlands). pMad was visualized by combining a fluorescent secondary diluted 1:1000 (goat anti-rabbit AlexaFluor-568, Invitrogen) with a fluorescent tertiary antibody, diluted 1:1000 (donkey anti-goat AlexaFluor-568, Invitrogen). The active zone-associated protein Brp was immunolabeled using a mouse NC82 Mab (1:100, Developmental Studies Hybridoma Bank) and goat anti-mouse Alexa-568 (1:1000, Invitrogen). DAB-stained preparations were mounted in glycerol, and fluorescent preparations were mounted using the Slowfade Antifade Kit from Invitrogen.

Microscopic imaging. For fluorescent imaging, $1 \mu \mathrm{m}$ optical sections were collected on either a Bio-Rad 1024 confocal system with a $40 \times$ Planapochromat 1.0 NA objective or a Zeiss LSM 510 with a $40 \times$ Planapochromat 1.3 NA objective. Comparative pMad and Brp staining within the third instar larval brain and at the muscle fiber (mf) $12 \mathrm{NMJ}$ was performed by labeling 3 or 4 animals of each genotype or condition in the same well, mounting them adjacently, and visualizing the fixed preparations using the same acquisition parameters. Deconvolution of the Brp images was performed with Imaris Autoquant (Bitplane AG), and all measurements were performed in Adobe Photoshop.

NMJ size was quantified from anti-HRP-labeled and DAB-stained NMJs using bright-field imaging. All data were taken from muscles in abdominal segments A3 and A4. Data from mfs 7 and 6 are shown, but similar phenotypes were observed on a variety of muscles, including $\mathrm{mfs}$ $13,12,5,4$, and 1 . The degree of motoneuron branching was quantified on $\mathrm{mfs} 13$ and 12 by scoring the proportion of NMJs whose highest order branch was either a primary, secondary, or tertiary (or greater) process. An NMJ branch was defined as a motoneuron process with 3 or more synaptic boutons. All synaptic boutons on a given muscle were scored and classified by bouton type (Ruiz-Cañada and Budnik, 2006). The size of muscle fibers across all control conditions and for the $\mathrm{Mad}^{1}$ expressing animals did not differ significantly. Muscles in $g b b$, wit, and mad mutants were smaller than their controls, yet normalization to muscle surface area had no effect on the significance of the data or conclusions. The data are presented as the absolute number of boutons. Bouton counts are reported as mean \pm SEM and analyzed for significance using a one-way ANOVA followed by a post hoc analysis with two tailed $t$ tests.

Electrophysiology. Third instar larvae were dissected and recorded with $3 \mathrm{M} \mathrm{KCl}$ sharp microelectrodes (35- $45 \mathrm{M} \Omega$ resistance) as previously described (Mosca et al., 2005). The bath saline contained $140 \mathrm{~mm} \mathrm{NaCl}, 5$ mм KCl, $1 \mathrm{~mm} \mathrm{CaCl}_{2}, 4 \mathrm{~mm} \mathrm{NaHCO}_{3}, 6 \mathrm{~mm} \mathrm{MgCl}_{2}, 5 \mathrm{~mm}$ TES, $5 \mathrm{~mm}$ Trehalose, 50 mu sucrose, and pH'd to 7.2 with $\mathrm{NaOH}$. Stimulus protocols were delivered with suction electrodes to a small portion of the compound nerve when recording from $\mathrm{mf} 6$ or to the axonal segment between $\mathrm{mf} 13$ and $\mathrm{mf} 12$ when recording from $\mathrm{mf} 12$. All recordings were taken from abdominal segments A3 and A4. PClamp 9.0 software (Molecular Devices) was used to implement stimulus protocols and to record signals, which were collected at $10 \mathrm{kHz}$ with a Dagan 8500 twoelectrode voltage-clamp amplifier. The signals were then filtered using a Gaussian filter with $3 \mathrm{kHz}$ cutoff. All recordings were performed at room temperature, $\sim 22^{\circ} \mathrm{C}$. Quantal content was computed as the mean excitatory junctional potentials (EJPs)/mean miniature EJPs (mEJPs) for synaptic potentials evoked from the large (type $\mathrm{I}_{\mathrm{B}}$ ) terminal and the combined large and small (type $\mathrm{I}_{\mathrm{S}}$ ) terminals.

$P C R$. RNA was isolated from the CNS of mature third instar WT, $w_{i t}^{A 12} / w_{i t}^{B 11}$, and $y w$; UAS-Mad ${ }^{1}$; ELAV-GS-GAL4 larvae grown in the presence or absence of RU-486. Dissected brains were rinsed with bath saline, quickly frozen in Trizol (Invitrogen), and homogenized in Trizol before RNA purification with standard procedures. CDNA was generated using 1 $\mu \mathrm{g}$ of total RNA, an oligo (dT) 18 primer, and Superscript II (Invitrogen). Transcript levels were quantified by qPCR performed in a $10 \mu \mathrm{l}$ reaction volume with a LifeTech (ABI) 7900 using a Power SYBR Green Real-time PCR Master Mix (Applied Biosystems). Reactions were run in triplicate with three biological replicates and average fluorescence $C_{t}$ values were obtained. Quantification of the transcript level of genes was accomplished using the relative quantification method (Livak and Schmittgen, 2001). qPCR primers unique to Lar and FmrF were selected and list as follows: Lar F: 5'TCTCTCAAGGATGGCTTCCTGCAA-3', Lar R: 5'-TTGAGTTCTCAGCCACACACTCGT3'; FmrF F: 5'-TATGGATCGGTATGGCAGAG A-3', FmrF R: 5'-TCCAAAGCAGGACTTCATGAG-3'. To normalize the results, $E L A V$, and $R p S 3$ were used as endogenous reference primers: ELAV-F: 5' -ACCAAAGTCCTGGACAACCGAAGA-3', ELAV-R:5'-CCTT GATGTCACGCACGATT-3'; RpS3-F: 5'-TTGCTATGGTGTGCTCCGCT ACAT-3', RpS3 R: 5'-ACGAATTTCATCGACTTGGCACGC-3'.

\section{Results}

Expression of a Mad dominant-negative transgene reveals that an early period of Mad signaling promotes NMJ growth Secretion of the BMP 4/5/6 homolog Glass bottom boat (Gbb) from postsynaptic muscle fibers stimulates presynaptic growth and development at the Drosophila NMJ. Gbb activates a presynaptic receptor complex containing the type II BMP receptor Wishful thinking (Wit), which is endocytosed and retrogradely transported to the motoneuron nucleus (Smith et al., 2012). Wit and its receptor complex then phosphorylate Mad, the SMAD1 transcription factor (pMad). Loss of function $g b b$, wit, and mad mutants each have approximately one-half of the WT number of synaptic boutons and lack normal pMad labeling in the motoneuron nucleus and at synaptic boutons (Aberle et al., 2002; Marqués et al., 2002; McCabe et al., 2003, 2004; Keshishian and Kim, 2004). NMJ growth and pMad localization can be restored in the corresponding mutants by presynaptic expression of either Wit or Mad, or by postsynaptic expression of Gbb (McCabe et al., 2003, 2004). However, pMad localizes to motoneuron nuclei during all stages of larval development (embryo, first, second, and third larval instars; E, L1-L3), yet the most robust NMJ growth occurs $2 \mathrm{~d}$ after synapse formation (during L2 and L3) (Keshishian et al., 1993; Broadie and Bate, 1993; Zito et al., 1999; Collins et al., 2006; Wang et al., 2007).

We addressed the discrepancy between nuclear pMad localization and NMJ growth by controlling the expression of $\mathrm{Mad}^{1}$, the protein encoded by the $\mathrm{mad}^{1}$ mutation. The $\mathrm{Mad}^{1}$ protein has a single residue change within its DNA-binding sequence (Takaesu et al., 2005), causing it to act as a dominant-negative and to phenocopy BMP loss of function mutations (see Materials and Methods) (Allan et al., 2003; Takaesu et al., 2005; Eade and Allan, 2009). To control the timing of $\mathrm{Mad}^{1}$ expression, we used the GeneSwitch GAL4 system (GS-GAL4), a modification of the GAL4-UAS system where a steroid-inducible fusion protein of GAL4 and the human progesterone receptor (GS-GAL4) are used to express UAS transgenes. GS-GAL4 driver lines are activated when RU-486 (mifepristone) is provided in the food (Osterwalder et al., 2001). The pan-neural ELAV-GS-GAL4 induces GFP expression in the CNS after larvae have been exposed to RU-486 for $5 \mathrm{~h}$, with peak expression occurring $12 \mathrm{~h}$ after the start of feeding (Osterwalder et al., 2001).

When $\mathrm{Mad}^{1}$ was expressed throughout embryonic and larval development (see Materials and Methods), we observed a strong suppression of synaptic growth, resulting in NMJs that were similar in size to those observed in mad mutants ( $\mathrm{mfs} 7$ and 6, WT control: $84.2 \pm 4.5, \mathrm{mad}^{1} / \mathrm{mad}^{12}: 43.5 \pm 4.0, p<10^{-5}$; $\mathrm{Mad}^{1}$ driven by ELAV-GS-GAL4 $\left(E L A V>\mathrm{Mad}^{1}+\mathrm{RU}\right): 52.7 \pm 2.8$; $p=0.08)$. We also observed a strong effect on NMJ branching. The percentage of synapses onto mfs 12 and 13 with tertiary or higher branch order was significantly reduced $(\mathrm{WT}=48 \%$, $\mathrm{mad}^{1} / \mathrm{mad}^{12}=7 \%, E L A V>\mathrm{Mad}^{1}+\mathrm{RU}=14 \%$; WT vs $\mathrm{mad}^{1} /$ $\operatorname{mad}^{12}, p=0.007 ;$ WT vs ELAV $>$ Mad $^{1}+\mathrm{RU}, p=0.003 ; \mathrm{mad}^{1} /$ $\mathrm{mad}^{12}$ vs $E L A V>\mathrm{Mad}^{1}+\mathrm{RU}, p=0.22$ ). By contrast, the overexpression of a single copy of WT Mad in presynaptic mo- 
toneurons did not have any observable effects on NMJ growth (data not shown).

Having found that pan-neural $\mathrm{Mad}^{1}$ induction throughout embryonic and larval development effectively reduces NMJ size (Fig. 1b, first two bars), we systematically presented RU-486 to activate $\mathrm{Mad}^{1}$ at different stages of development to estimate when Mad activity is required for NMJ growth. We first examined the effect of presenting RU-486 at successively earlier stages of larval development (Fig. 1b, bars 3-5). No significant effect was seen when RU-486 was presented during the last larval instar (L3; Fig. $1 b$, bar 3), or in both L2 and L3 (Fig. 1b, bar 4), a period of $3 \mathrm{~d}$ when most bouton addition takes place (Keshishian et al., 1993; Zito et al., 1999). By contrast, presenting the inducing agent throughout larval development (L1-L3) resulted in a significant reduction in NMJ size (Fig. $1 b$, bar 5 ). We next examined the effect of presenting the inducing agent at successively later stages of development (Fig. 1b, bars 6-8). When RU-486 induction was limited to the embryonic stage (Fig. $1 b$, bar 6; see also Materials and Methods), the NMJ was of normal size. By contrast, a suppression of growth occurred when induction was also provided during L1 (Fig. 1b, bar 7). Continued exposure to the inducing agent through L2 did not further suppress synaptic growth (Fig. $1 b$, bar 8 ).

These results suggest that RU-486 feeding during L1, to inhibit Mad function during that period of development, had a strong effect on later NMJ growth. To address this directly, we next exposed animals to the inducing agent during the E, L2, and L3 stages, but not L1 (Fig. 1 $a$, top, $b$, bar 9) or alternatively, only during L1 (Fig. $1 a$, bottom, $b$, bar 10). The results indicate that NMJ growth is strongly suppressed when $\mathrm{Mad}^{1}$ is induced during the L1 stage of larval development, a period that precedes the majority of NMJ growth. Induction at all times before and after that time had minimal effects on growth. These results are consistent with retrograde BMP signaling during $\mathrm{L} 1$ promoting NMJ growth over the next $3 \mathrm{~d}$ of development.

\section{The temporally controlled rescue of $g b b$ mutants during $\mathrm{L} 1$ is} sufficient for NMJ growth

Expression of Gbb in the postsynaptic muscles of $g b b$ mutants can rescue NMJ size (McCabe et al., 2003), yet Gbb released in the CNS strengthens synapses between interneurons and motoneurons (Baines, 2004). Stronger interneuron-motoneuron synapses may also contribute to NMJ growth. We therefore examined whether induction of Gbb expression in muscle during L1 similarly rescued NMJ size. Using an inducible muscle-specific MHCGS-GAL4 driver, we expressed a WT Gbb transgene $(\mathrm{MHC}>$ $G b b+\mathrm{RU})$ in the muscles of $g b b$ mutants and induced expression using the RU-486 feeding regimen as described above for $\mathrm{Mad}^{1}$. We analyzed synaptic morphology in mature L3 animals and also examined the localization of pMad to assess the activation of presynaptic BMP signaling.

Uninduced $g b b$ mutant larvae bearing the inducible transgene $(\mathrm{MHC}>g b b-\mathrm{RU})$ had small NMJs, similar in size to heteroallelic $g b b$ mutants (Fig. $2 a$, bar 1 ; mfs 7 and 6, MHC $>g b b-$ RU: $50.1 \pm 2.8 ; g b b^{1} / g b b^{2}$, denoted by the open arrowhead: $43.3 \pm 2.7$; $p=0.05)$. When RU-486 was fed throughout embryonic and larval development to drive expression of $\mathrm{Gbb}$ in muscle $(\mathrm{MHC}>g b b+\mathrm{RU})$, bouton numbers were fully rescued (Fig. $2 a$, bar 2, $p<0.005$; compare with the filled arrowhead, for WT), and we observed a small, though nonsignificant, increase in motoneuron branching (branching data, $\mathrm{WT}=46 \%, M H C>g b b$ $-\mathrm{RU}=5 \%$, and $M H C>g b b+\mathrm{RU}=10 \% ; M H C>g b b-\mathrm{RU}$ vs $M H C>g b b+\mathrm{RU}, p=0.38)$. As was found for the Mad ${ }^{1}$ expres- a
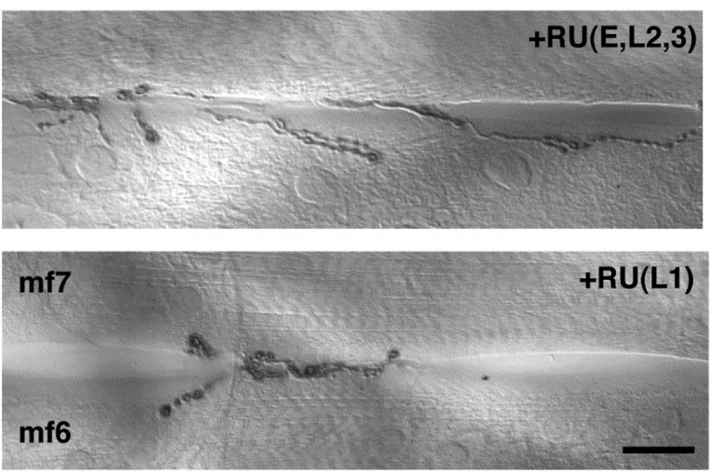

b
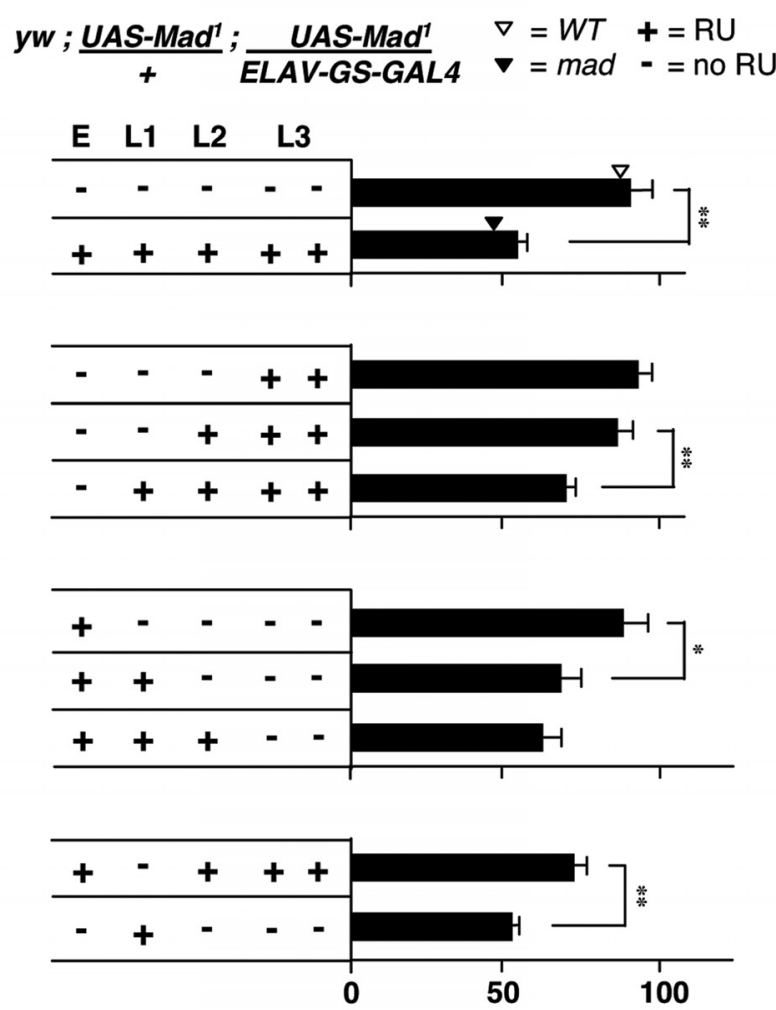

RU-486 Exposure Number of Boutons, $\mathrm{mf}$ 7/6

Figure 1. NMJ growth requires an early period of Mad signaling during the first larval instar (L1). $\boldsymbol{a}$, NMJs on $\mathrm{mf} 7 / 6$ from staged third instar larvae bearing an RU-486-inducible dominantnegative Mad $^{1}$ transgene driven in neurons ( $y w$; UAS-Mad ${ }^{7} /+$; UAS-Mad ${ }^{1} /$ ELAV-GS-GAL4). See Figure $2 b$ for a schematic diagram of the body wall musculature. Top, Normal-sized NMJ of an animal where expression of $\mathrm{Mad}^{1}$ was induced at all stages of development except $\mathrm{L} 1$ [ $+\mathrm{RU}$ $(E, L 2, L 3)]$. Bottom, Smaller NMJ of an animal where expression of Mad $^{1}$ was induced only during the L1 stage [+RU (L1)]. Scale bar, $20 \mu \mathrm{m}$. $\boldsymbol{b}$, The number of synaptic boutons on muscle fibers $\mathrm{mf} 7 / 6$ from staged third instar larvae bearing the RU-486-inducible dominantnegative Mad ${ }^{1}$ transgene. The developmental stages are indicated at the top (the E, L1, and L2 stages each last $1 \mathrm{~d}$, and the $\mathrm{L} 3$ stage lasts $2 \mathrm{~d}$ ). + , induction with RU-486; - , no induction. The top two bars show the effects of Mad ${ }^{1}$ induction throughout development compared with the effect of no induction. For reference, the average number of boutons observed in either WT controls (white arrowhead) or for the $\mathrm{mad}^{1} / \mathrm{mad}^{12}$ heteroallelic mutant (mad; black arrowhead) are indicated on the bars. The second group of three bars shows the effect of inducing expression of the $\mathrm{Mad}^{1}$ transgene at successively earlier stages of development. The third group of three bars shows the effect of inducing expression of the $\mathrm{Mad}^{1}$ transgene at successively later stages. The final two bars compare the effect of inducing expression at all times except $L 1$, or alternatively inducing expression only at L1. Images of the NMJs from these last two experiments are shown in $a .{ }^{*} p<0.05 .{ }^{* *} p<0.005$. 
a

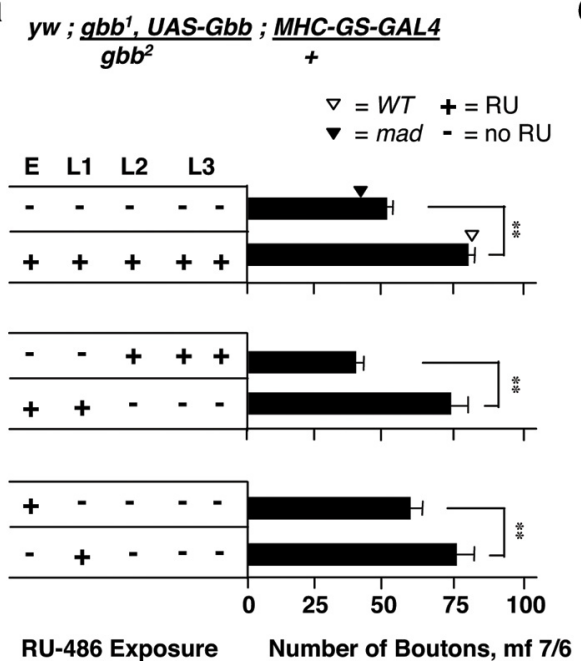

b

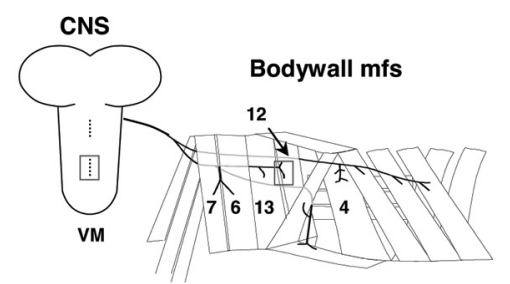

C
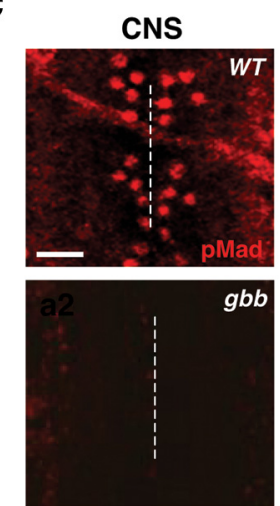

$g b b$
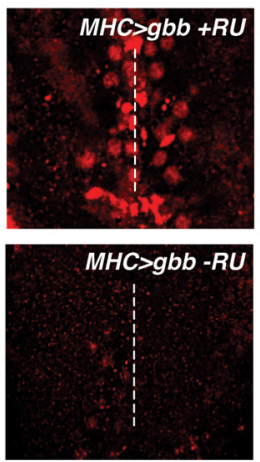

Figure 2. Phenocritical rescue of $g b b$ mutants indicates that signaling during $\mathrm{L} 1$ is sufficient for NMJ growth. $\boldsymbol{a}$, The number of synaptic boutons on staged, third instar mf $7 / 6$ NMJs in animals mutant for the BMP ligand $g b b$ and bearing an RU-486-inducible Gbb transgene driven in muscle fibers ( $\left.w ; g b b^{1}, U A S-g b b / g b b^{2} ; M H C-G S-G A L 4 /+\right)$. +, induction with RU-486; - , no induction. The top two bars show the effects of Gbb induction throughout development compared with the effect of no induction. For reference, the average number of boutons observed in either WT controls (white arrowhead) or for the $g b b^{1} / g b b^{2}$ mutations ( $g b b$; black arrowhead) are indicated on the bars. The second pair of bars shows the effect of rescuing the gbb mutants by inducing expression of $\mathrm{Gbb}$ in muscle fibers during late stages ( $\mathrm{L} 2$ and $\mathrm{L} 3$ ) compared with induction at early stages ( $E$ and $L 1)$. The third pair of bars shows the rescuing effect of inducing expression either in the E or L1 stage. $\boldsymbol{b}$, Schematic diagram of the larval CNS and key body wall muscle fibers. Boxes represent the approximate locations of the images in c. VM, Ventral midline. c, Immunolabeling of pMad in neuronal nuclei within the ventral ganglion (left column) and at the periphery in synaptic boutons (right column). The top row shows WT labeling; the second row of images is from a gbb mutant ( $g b b^{1} / g b b^{2}$ ), the third and fourth rows of images are from a gbb larvae carrying a UAS-Gbb transgene ( $w ; g b b^{1}, U A S-g b b^{1} / g b b^{2} ; M H C-G S-G A L 4 /+$ ) either with (third row; MHC $\left.>g b b+R U\right)$ or without induction (fourth row; $M H C>g b b-\mathrm{RU}$ ) by RU-486. The synaptic boutons on $\mathrm{mf} 12$ are located to the right of the dashed line. Scale bars: ganglion, $20 \mu \mathrm{m}$; synaptic boutons, $10 \mu \mathrm{m} .{ }^{* *} p<0.005$.

sion analysis, RU-486 induction during the L2 and L3 stages failed to restore NMJ size (Fig. 2a, bar 3), whereas induction during E and L1 produced a significant rescue (Fig. 2a, bar 3). The data indicate a critical or sensitive period during early development, before the major NMJ expansion in L2 and L3. This was confirmed by limiting Gbb induction solely to L1 (Fig. 2a, bar 6), whereas induction in the embryo alone failed to restore normal NMJ size (Fig. 2a, bar 5).

We verified that Gbb expression in muscle was sufficient to activate pMad, as assessed by its localization in the nuclei of motoneurons, where it is involved in gene transcription. We monitored pMad immunofluorescence in WT, $g b b$ mutants, and in $g b b$ mutants whose muscles expressed Gbb (Fig. 2c). In WT third instar larvae, pMad-immunopositive labeling is readily observed within the CNS as well as at NMJ boutons (Fig. $2 c$, WT; refer to Fig. $2 b$ for the corresponding sampling areas). By contrast $g b b^{1} /$ $g b b^{2}$ mutant larvae showed barely detectable immunofluorescence at both the central and peripheral sites (Fig. $2 c, g b b$ ). Restoring Gbb expression throughout development in muscle restored pMad immunofluorescence to both sites, confirming that the loss of pMad in the mutants results from the loss of Gbb

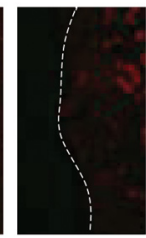

mf12
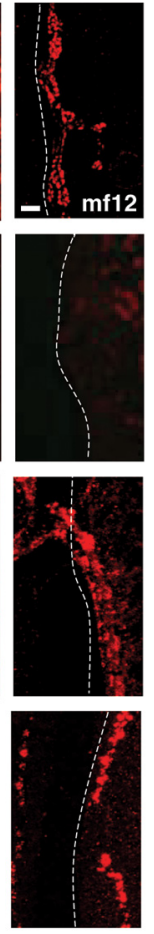

(Fig. $2 c, M H C>g b b+\mathrm{RU}$ ). We did observe staining at the NMJ in uninduced larvae (Fig. 2c, $M H C>g b b-\mathrm{RU}$ ), which we suspect results from leakiness of the MHC-GS driver (independent of RU486) that occurs in late third instar (Nicholson et al., 2008). These patterns of labeling are consistent with a model where Gbb, released from muscle, activates BMP signaling at the NMJ where the type I and II receptors (including Wit) reside, and through retrograde mechanisms, leads to the presence of the activated transcription factor in the nuclei of motoneurons.

\section{Phenocritical rescue of wit mutants with the TARGET system indicates an early requirement for Wit}

A role for early retrograde BMP signaling was also revealed by examining the phenocritical rescue of wit mutants using a Wit transgene. We used the TARGET system of temperature-dependent $\left(18^{\circ} \mathrm{C}\right.$ vs $\left.30^{\circ} \mathrm{C}\right)$ transgene expression (see Materials and Methods) and ELAV-GAL4 to drive a UAS-Wit-GFP construct in presynaptic motoneurons. An important aspect of these experiments is that the hightemperature rearing required for Wit expression also elevates locomotor and electrical activity, causing NMJs to grow twice the WT size (Sigrist et al., 2003; Zhong and $\mathrm{Wu}, 2004)$. This allowed us to simultaneously examine the role of Wit signaling in activity-dependent synaptic plasticity. Control experiments on the WT verified that NMJ size is increased by high temperature $\left(30^{\circ} \mathrm{C}\right)$ but is not reduced by low temperature $\left(18^{\circ} \mathrm{C}\right)$ (Fig. $3 a$, bars 1-3). High-temperature rearing also had no effect on NMJ expansion in wit mutants (Fig. 3a, compare bars 4 and 6). Pan-neural induction of the Wit receptor throughout embryonic and larval development effectively restored the enlarged NMJ size (Fig. 3b, compare bars 1 and 2). This indicates that Wit signaling may be required for activity-dependent synaptic growth at the NMJ.

Consistent with our results for Mad and Gbb, hightemperature rearing and induction of Wit during L2 and L3 had no effect on NMJ size (Fig. 3b, bar 3). By contrast, induction during $\mathrm{E}$ and $\mathrm{L} 1$ resulted in enlarged NMJs that were equal in size to synapses in temperature-treated WT animals (compare Fig. $3 b$, bar 4 with Fig. $3 a$, bar 3). When we attempted to dissect the early requirement of Wit by inducing receptor expression at either E or L1, we were surprised to find that induction in the embryo resulted in a partial restoration of NMJ growth (Fig. 3b, compare bars 2, 4, and 5), whereas induction in L1 showed no rescue (Fig. 3b, bar 6). One explanation for the apparent embryonic requirement for Wit in contrast to the later $\mathrm{L} 1$ requirement for $\mathrm{Gbb}$ and Mad could be the time needed for transgene expression, transport, and function. Gbb and $\mathrm{Mad}^{1}$ are both transcribed and translated in close proximity to where they exert their actions: Gbb is expressed by muscle nuclei within a few microm- 
a

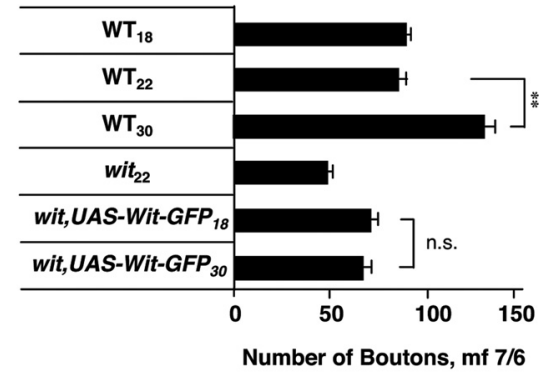

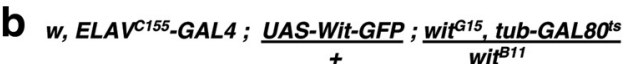
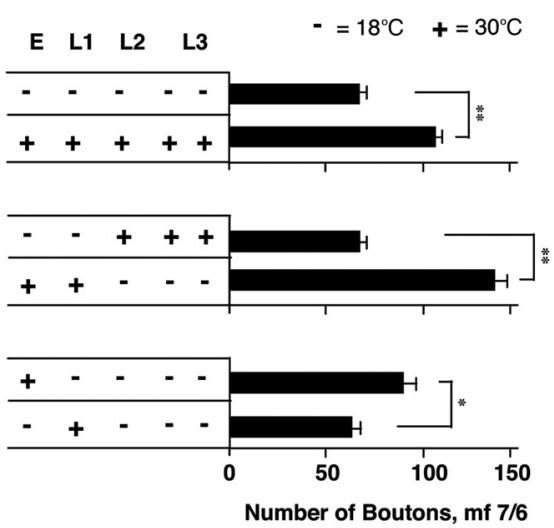

Figure 3. The NMJ growth defects caused by wit mutations can be rescued by neuronal expression of Wit during $\mathrm{E}$ and L1. $\boldsymbol{a}$, The effect of rearing temperature $\left(18^{\circ} \mathrm{C}, 22^{\circ} \mathrm{C}\right.$, or $30^{\circ} \mathrm{C}$ throughout development) on the number of synaptic boutons on $\mathrm{mf} 7 / 6$ in WT third larval instar animals raised at each of the three temperatures (top 3 bars; $\mathrm{WT}_{18}, \mathrm{WT}_{22}, \mathrm{WT}_{30}$ ). The fourth bar represents bouton numbers for wit $^{B 11} /$ wit $^{615}$ mutant larvae raised at $22^{\circ} \mathrm{C}\left(\right.$ wit $\left._{22}\right)$. The fifth and sixth bars represent bouton numbers for wit animals raised at either $18^{\circ} \mathrm{C}$ or $30^{\circ} \mathrm{C}$ bearing the UAS-Wit-GFP transgene and the temperature-sensitive tub-GAL80 ts suppressor of Gal 4 activity, but without the Gal4 driver (wit, UAS-Wit-GFP 18 and wit, UAS-Wit-GFP ${ }_{30}$; UAS-Wit-GFP/+; wit $^{B 11} /$ wit $^{615}$, tub-GAL80 ${ }^{\text {t5 }}$. The top 3 bars represent the NMJ expansion associated with hightemperature rearing $\left(30^{\circ} \mathrm{C}\right)$; the bottom three bars represents the absence of an expansion in animals possessing a wit mutation. $\boldsymbol{b}$, NMJ synaptic bouton counts on $\mathrm{mf} 7 / 6$ in wit mutant larvae with expression of a Wit-GFP transgene induced at various stages of development using the temperature-dependent TARGET system (see Materials and Methods). At $18^{\circ} \mathrm{C}(-)$, Wit expression is suppressed. At $30^{\circ} \mathrm{C}(+)$, Wit expression is induced. The top pair of bars compares the effect of no induction of Wit $\left(18^{\circ} \mathrm{C}\right)$ to that of induction throughout development $\left(30^{\circ} \mathrm{C}\right)$. The second pair of bars compares the effect of late (third bar, L2 and L3) versus early (fourth bar, $E$ and $L 1$ ) induction. The third pair of bars compares induction only during $E$ (fifth bar) with that of induction during $\mathrm{L} 1$ (sixth bar). ${ }^{*} p<0.05 .{ }^{* *} p<0.005$. n.s., Not significant.

eters of where it is released, and $\mathrm{Mad}^{1}$ is expressed at the motoneuron cell body where it should exert its dominant-negative actions. By contrast, more time may be required to express and transport Wit from the motoneuron cell body to the NMJ in sufficient quantities to mediate BMP signaling during the L1 stage.

Canonical retrograde signaling is required for activitydependent growth plasticity

The above results show that, in addition to normal growth, the activity-dependent expansion of the NMJ may also require BMP signaling. Motoneuron activity is a potent regulator of NMJ development, with increased action potential firing rates leading to a greater number of synaptic boutons and more complex axon branching profiles. This developmental plasticity was first described in hyperexcitable $\mathrm{K}^{+}$channel double-mutants such as eag $S h$, whose motoneurons show robust spontaneous action poten- a

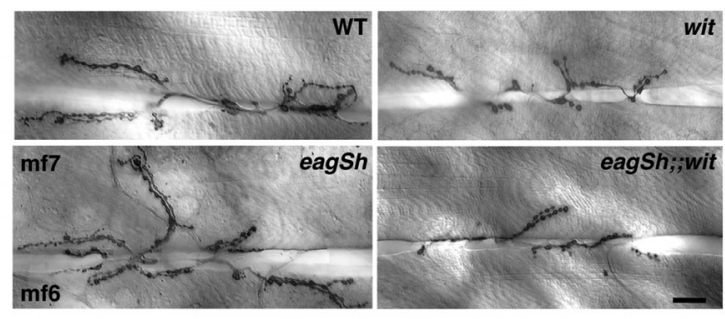

b

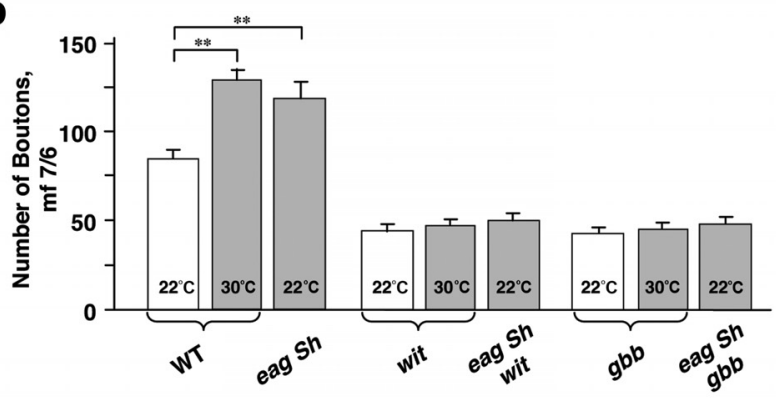

C

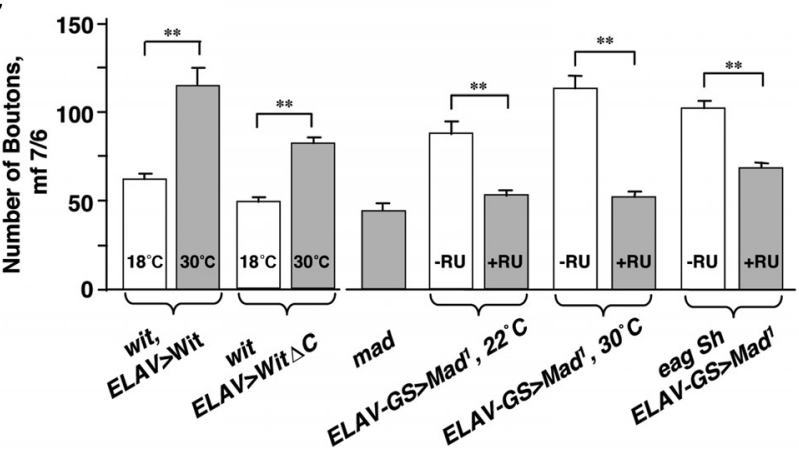

Figure 4. Canonical BMP signaling is required for the activity-dependent expansion of the NMJ. $\boldsymbol{a}$, Representative NMJs on $\mathrm{mf} 7 / 6$ in third instar larvae, illustrating the NMJ expansion associated with eag Sh, and the absence of an eag Sh-dependent expansion in wit mutants. Genotypes: WT, wit (wit ${ }^{A 12} /$ wit $\left.^{B 11}\right)$, eag Sh (eag ${ }^{1} h^{120}$ ), and eag Sh;; wit (eag ${ }^{1} S^{120} / Y_{; ;}$wit $^{B 11}$ / $\left.\operatorname{Df}(3 L)^{c 175}\right)$. Scale bar, $25 \mu \mathrm{m}$. $\boldsymbol{b}$, The number of synaptic boutons on $\mathrm{mf} 7 / 6$ of third instar larvae, illustrating the dependence on BMP signaling (revealed by either wit or $g b b$ mutations) for NMJ expansion due to high-temperature rearing or eag $S h$-induced neuronal hyperactivity. Data were collected from WT animals reared at $22^{\circ} \mathrm{C}$ and $30^{\circ} \mathrm{C}$, eag Sh reared at $22^{\circ} \mathrm{C}$, wit reared at $22^{\circ} \mathrm{C}$ and $30^{\circ} \mathrm{C}$, eag Sh wit $\left(e a g^{7} \mathrm{Sh}^{120} / Y_{; ;}\right.$wit ${ }^{B 11} /$ wit $\left.^{615}\right), g b b\left(g b b^{7} / g b b^{2}\right)$ reared at $22^{\circ} \mathrm{C}$ and $30^{\circ} \mathrm{C}$, and eag Sh $g b b\left(e a g^{1} \mathrm{Sh}^{120} ; g b b^{1} / g b b^{2}\right)$.c, The dependence on BMP signaling for activitydependent NMJ expansion, tested by rescue of either wit mutations with a Wit transgenes and by dominant suppression of Mad signaling with the $\mathrm{Mad}^{1}$ transgene. NMJ sizes in control $\left(18^{\circ} \mathrm{C}\right)$

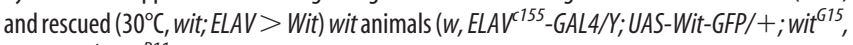
tub-Gal $80^{t 5} / w_{i t}^{B 11}$ ) and in animals rescued with a Wit transgene lacking its $C$ terminus (wit;

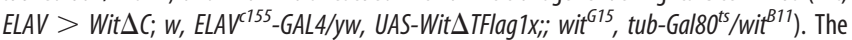

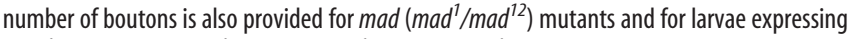
$\operatorname{Mad}^{1}$ (ELAV-GS > Mad $^{1} ;+;$ UAS-Mad ${ }^{1} /+;$ UAS-Mad ${ }^{1} /$ ELAV-GS-GAL4) upon rearing at $22^{\circ} \mathrm{C}$ and $30^{\circ} \mathrm{C}$ in the absence $(-\mathrm{RU})$ and presence ( $\left.+\mathrm{RU}\right)$ of RU-486. Synaptic size in eag Sh animals expressing Mad $^{1}$ (eag Sh, ELAV-GS $>$ Mad $^{1}$; eag $^{1}$ Sh $^{120} / Y$; UAS-Mad ${ }^{7} /+;$ UAS-Mad $^{1} /$ ELAV-GSGAL4) with and without RU-486 is also shown. ${ }^{* *} p<0.005$.

tial firing that is suppressed by the $\mathrm{Na}^{+}$channel blocker TTX or by mutations that affect para, the $\mathrm{NaV} 1$ voltage-gated $\mathrm{Na}$ channel (Ganetzky and Wu, 1982, 1983; Budnik et al., 1990). Similar effects are observed when flies are reared in a high-temperature environment, where locomotor activity and motoneuron firing rates are also enhanced (Sigrist et al., 2003; Zhong and Wu, 2004; Peng et al., 2007).

We therefore examined the synapses of eag Sh; gbb and eag Sh;; wit triple mutants, finding small NMJs that resemble those of $g b b$ and wit rather than the expanded synapses of eag $S h$ (Fig. 4a,b). Bouton numbers at these synapses were half the WT level as 
a1

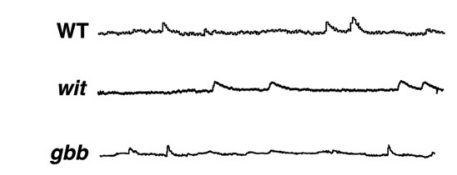

a2
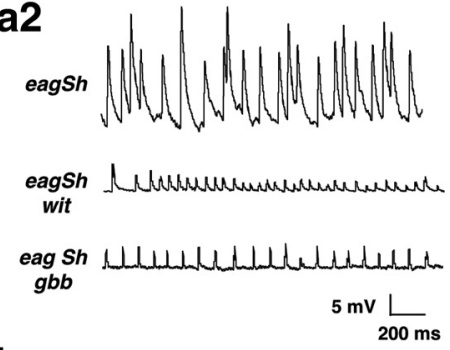

b

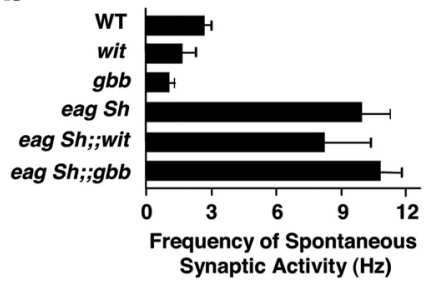

C

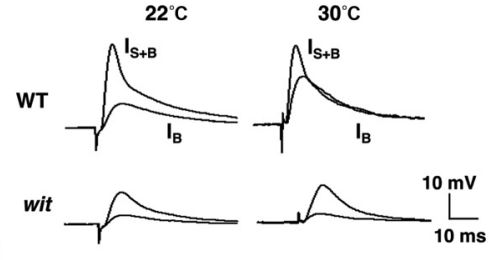

d

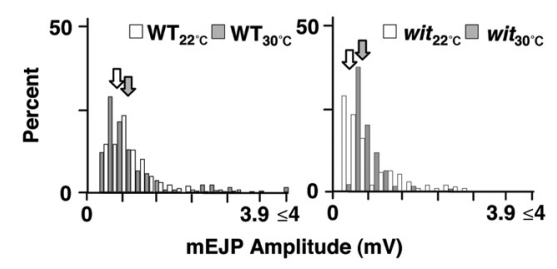

e

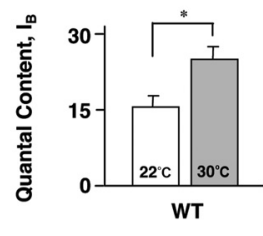

eag Sh; wit and eag Sh; gbb larvae exhibited spontaneous synaptic depolarizations that were as frequent as in eag Sh (Fig. $5 a, b$; eag Sh vs eag Sh; wit $p=0.21$, eag Sh $v$ s eag Sh; $g b b p=0.43)$. The amplitude of the activity was nevertheless smaller than in eag Sh (eag Sh vs eag Sh; wit $p<10^{-5}$, eag $S h$ vs eag $S h ; g b b p<10^{-5}$ ). wit mutations also blocked a temperature-induced increase in EJP size from the large, type $\mathrm{I}_{\mathrm{B}}$ boutons, which is quite robust in the WT (Sigrist et al., 2003; Zhong and $\mathrm{Wu}, 2004$; Fig. $5 c-e)(\mathrm{mf} 12, \mathrm{IB}$, mean $\pm \mathrm{SEM}, \mathrm{mV}$; WT22: $9.58 \pm 0.85$, WT30: $15.2 \pm 1.67$, $p=0.008$; wit22: $4.90 \pm 0.14$, wit30: $3.98 \pm 0.85, p=0.20)$. The size of mEJPs was unaltered (Fig. 5d), and their frequency was unaffected (data not shown), consistent with a presynaptic effect on the quantal content of glutamate release (Fig. 5e). Therefore, without BMP signaling, neither morphological nor physiological plasticity is possible at the Drosophila NMJ, and we conclude that the loss of activity-dependent plasticity in BMP signaling mutants is not a secondary effect of reduced membrane excitability.

Figure 5. BMP pathway mutations block the activity-dependent modulation of synaptic transmission without suppressing hyperexcitability. $\boldsymbol{a}$, Intracellular records of spontaneous synaptic depolarizations in $\mathrm{mf} 12$ from third instar larvae, recorded at $22^{\circ} \mathrm{C}$ in $1 \mathrm{~mm} \mathrm{Ca}{ }^{2+}$ saline. a1, Records from WT, wit $\left(\right.$ wit $\left.^{A 12} / w_{i t}^{B 11}\right)$, and $g b b\left(g b b^{1} / g b b^{2}\right)$. a2, Records from eag Sh $\left(e a g^{1} S^{120}\right)$, eag Sh;; wit $\left(\mathrm{eag}^{1} \mathrm{Sh}^{120}\right.$;; wit $^{A 12} /$ wit $\left.^{615}\right)$, and eag Sh; gbb (eag $\left.\mathrm{Sh}^{120} ; g b b^{1} / g b b^{2}\right)$. The activity in eag Sh mutants has been previously shown to be blocked by TTX (Ganetzky and Wu, 1982) and is the result of motoneuron action potential activity. All spontaneous activity was recorded for at least $10 \mathrm{~s}$, and recordings were performed after cutting the peripheral nerve close to the ventral ganglia. $\boldsymbol{b}$, The frequency of spontaneous synaptic activity in the corresponding genotypes shown in $\boldsymbol{a}$. BMP mutations do not significantly impact the frequency of spontaneous synaptic activity in eag Sh. C, EJPs recorded from WT and wit ( wit $^{A 12} /$ wit $^{B 11}$ ) animals reared at $22^{\circ} \mathrm{C}$ and $30^{\circ} \mathrm{C}$. The type $I_{B}$ motoneuron $\left(I_{B}\right)$ EJP was separated from the summed type $I_{B}$ and $I_{S}\left(I_{S+B}\right)$ EJP by control of the stimulus amplitude and duration. The $\mathrm{I}_{\mathrm{B}}$ and $\mathrm{I}_{\mathrm{S}}$ motoneuron axons differ in diameter and exhibit differential action potential thresholds during extracellular stimulation; $22^{\circ} \mathrm{C}$ (room temperature); $1 \mathrm{~mm} \mathrm{Ca}{ }^{2+} . \boldsymbol{d}$, Amplitude distribution of $\mathrm{mEJPs}$ from WT and wit reared at $22^{\circ} \mathrm{C}$ (white bars) and $30^{\circ} \mathrm{C}$ (gray bars); $\mathrm{WT}_{22^{\circ}{ }^{\circ},} N=16$ animals; $\mathrm{WT}_{30^{\circ} \mathrm{C}}, \mathrm{N}=5 ;$ wit $_{22^{\circ} \mathrm{C},}, \mathrm{N}=6 ;$ wit $_{30^{\circ} \mathrm{C}}, \mathrm{N}=13$. Bin size, $0.2 \mathrm{mV}$. Arrows indicate the mean mEJP amplitudes, which were not statistically different. $\boldsymbol{e}$, Quantal content is shown for the $\mathrm{I}_{\mathrm{B}}$ terminal as defined by the ratio of EJP/mEJP $\left(\mathrm{WT}_{22^{\circ} \mathrm{C},} n=13 ; \mathrm{WT}_{30^{\circ} \mathrm{C},} n=5 ;\right.$ wit $_{22^{\circ} \mathrm{C},} n=5 ;$ wit $\left._{30^{\circ} \mathrm{C},}, n=7\right) .{ }^{*} p<0.05$.

assessed on multiple muscles ( $\mathrm{mfs} 6,7,12,13,5,4$, and 1 ). Branching profiles on $\mathrm{mfs} 12$ and 13 were correspondingly simple (WT: percentage NMJs with tertiary or higher branch order $48 \%$; eag Sh: 93\%; wit: 15\%; eag Sh; wit: 10\%; gbb: 30\%; and eag Sh; $g b b: 8 \%)$. Similar results were obtained with eag Sh; wit over a wit deficiency (Fig. 4a). Using high temperature to increase activity was equally ineffective: the NMJs at $30^{\circ} \mathrm{C}$ were similar in size to those seen at $22^{\circ} \mathrm{C}$ (Fig. $4 b$; WT $30^{\circ} \mathrm{C}$ : $83 \%$; wit $30^{\circ} \mathrm{C}: 2 \%$; $g b b$ $\left.30^{\circ} \mathrm{C}: 9 \%\right)$. Growth plasticity was partially rescued in wit mutants by a truncated Wit transgene (Wit $\Delta \mathrm{C}$ ) that lacks noncanonical signaling and causes Wit to signal exclusively through Mad (Fig. $4 c$; compare the bars 3 and $4, p<0.05$, and bars 2 and $4, p<0.05$ ) (Eaton and Davis, 2005). This suggests that much of the rescue is taking place through Mad, a view substantiated by the presynaptic expression of $\mathrm{Mad}^{1}$, which blocked the activity-dependent NMJ expansion due to eag $S h$ and high temperature (Fig. $4 c$, right). These findings indicate that activity-dependent plasticity at the NMJ requires retrograde BMP signaling through Mad.

An alternative explanation for these data is that BMP signaling mutations suppress activity despite the eag Sh mutations or hightemperature rearing. Physiological recordings from body wall muscles, however, showed that BMP pathway mutations did not suppress eag Sh-induced neuronal hyperactivity. The muscles of

\section{Retrograde BMP signaling permits NMJ growth and plasticity}

Our results are consistent with a model where retrograde BMP signaling switches on developmental programs that enable activity-dependent NMJ growth. This is in contrast to situations where the level of BMP signaling determines the amount of NMJ growth and plasticity. To distinguish between these scenarios, we tested whether there is a synergistic relationship between the level of BMP signaling and NMJ activity. We used two constitutively active variants of the type I BMP receptor (Saxophone, Sax ${ }^{\text {Act }}$ or Thickveins, Tkv ${ }^{\text {Act }}$ ) at gene dosages that by themselves do not lead to NMJ expansion (McCabe et al., 2004; Collins et al., 2006). These transgenes were combined with a mutation $\left(\mathrm{Sh}^{\mathrm{M}}\right)$ or a rearing condition $\left(25^{\circ} \mathrm{C}\right)$ that moderately elevate neural activity, but also do not expand the NMJ (Budnik et al., 1990; Zhong and Wu, 2004). We found no evidence of synergy between elevated BMP activity and neural activity with respect to NMJ growth. Third instar $S h^{M}$ motoneurons expressing Sax ${ }^{\text {Act }}$ or $\mathrm{Tkv}^{\text {Act }}$ formed NMJs similar in size to those of $S h^{M}$ mutants. Similarly, larvae reared at $25^{\circ} \mathrm{C}$ in combination with $\mathrm{Sax}^{\mathrm{Act}}$ or $\mathrm{Tkv}^{\mathrm{Act}}$ expression had WT-sized NMJs (Fig. 6b). Elevating activity to a higher level, using the hyperactive eag $S h$ mutation, still did not yield a synergistic interaction with $\mathrm{Tkv}^{\text {Act }}$ (Fig. 6b, last two bars).

Finally, we determined at what stage of development Mad signaling is required for activity-dependent NMJ expansion. Hyperactive NMJs showed a very robust NMJ expansion when the dominant-negative $\mathrm{Mad}^{1}$ transgene was expressed in neurons at all developmental stages except L1 (Fig. $6 c$; ELAV $>\mathrm{Mad}^{1}+\mathrm{RU}$ (E, L2, L3) in eag Sh: $96.2 \pm 5.4 ; E L A V>M^{1}+R U$ (E, L2, L3): $70.9 \pm 3.6, p<0.05)$, whereas $\mathrm{Mad}^{1}$ expression during L1 suppressed growth plasticity as strongly as when it was expressed 
a

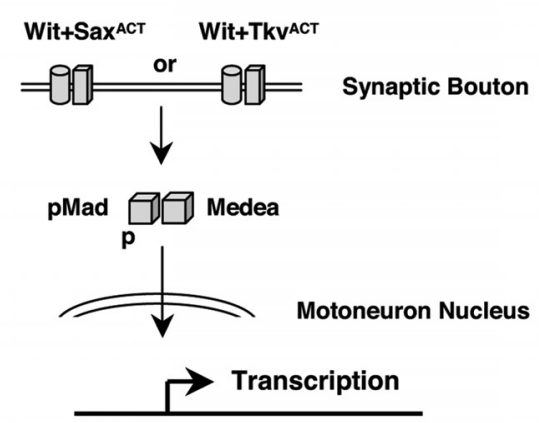

b

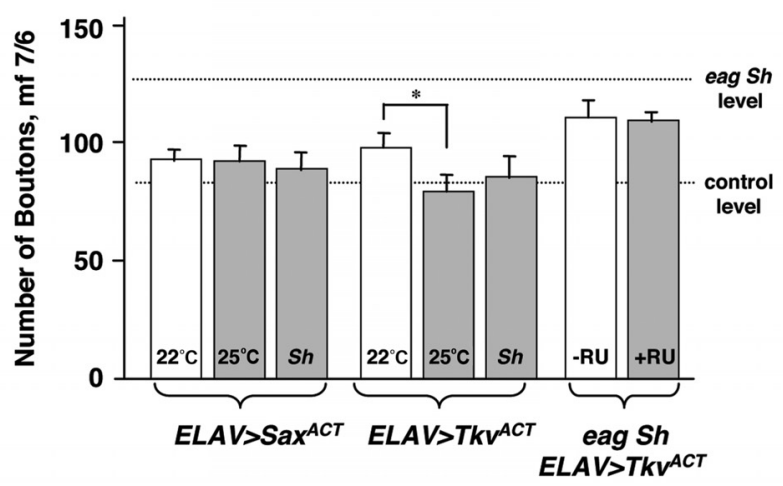

C

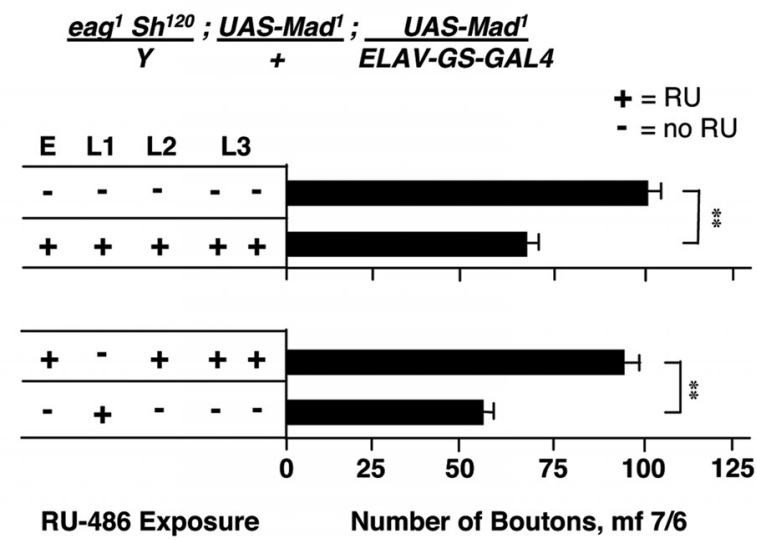

Figure 6. Activity and BMP signaling do not synergize to enhance NMJ size. $\boldsymbol{a}$, Diagram showing the BMP receptor complex at the motoneuron bouton membrane, composed of the type II BMP receptor Wit and either of the two type I BMP receptors, Saxophone and Thick veins. Constitutively active Saxaphone (Sax ${ }^{A C T}$ ) and Thick veins $\left(\mathrm{TkvA}^{\mathrm{ACT}}\right.$ ) receptors phosphorylate Mad (pMad) independent of binding by the Gbb ligand, leading to elevated pMad at the motoneuron nucleus. $\boldsymbol{b}$, The number of boutons on $\mathrm{mfs} 7 / 6$ after presynaptic expression of Sax ${ }^{\mathrm{ACT}}$ or $\mathrm{Tkv}^{\mathrm{ACT}}$ at $22^{\circ} \mathrm{C}$, at $25^{\circ} \mathrm{C}$, and in a $\mathrm{Sh}$ or eag $\mathrm{Sh}$ mutant background. The genotypes are as follows: Elav > Sax ${ }^{A C T}$ (ELAV ${ }^{C 155}$-GAL4/Y; UAS-Sax ${ }^{A C T}$ ), ELAV > TKV ${ }^{A C T}$ (ELAV ${ }^{C 155}$-GAL4/Y; UAS$\left.T k v^{A C T} /+\right)$ ), Sh background (Sh ${ }^{M}$, ELAV $^{C 155}$-GAL4/Y; UAS-SaX ${ }^{A C T}$ or UAS-TKV $\left.{ }^{A C T} /+\right)$, and eag Sh, $E L A V>T K V^{A C T}+\left(e^{a g} g^{1} S h^{120} / Y ; U A S-T k V^{A C T} /+; E L A V-G S-G A L 4 /+\right)$. These animals were grown in the absence $(-\mathrm{RU})$ or presence $(+\mathrm{RU})$ of RU-486. The lower dashed line represents the mean NMJ size in the GAL4 ( $w$, ELAV ${ }^{155}$-GAL4) and UAS ( $y w$, UAS-Sax ${ }^{A C T}$ and $y w$, UAS$T K V^{A C T}$ ) controls as well as in Sh${ }^{M}, E L A V^{C 155}$-GAL4 and the WT. The upper dashed line represents the mean synaptic size in eag Sh and in WT animals grown at $30^{\circ} \mathrm{C}$. c, The number of boutons on mfs $7 / 6$ in $\mathrm{eag}^{1} \mathrm{Sh}^{120} / \mathrm{Y}$; UAS-Mad $1+$; UAS-Mad ${ }^{7} /$ ELAV-GS-GAL4 animals grown without and with RU-486 throughout development. Also shown is the number of boutons in this genotype after RU-486 induction of $\mathrm{Mad}^{1}$ at all stages of development except during $\mathrm{L} 1$ or only during $\mathrm{L} 1$. + , induction with RU-486; - , no induction. ${ }^{*} p<0.05 .{ }^{* *} p<0.005$.

throughout development (Fig. 6c, compare bars 2 and 4). This indicates that there is an early critical or sensitive period during L1 when Mad signaling is necessary and sufficient to permit activity-dependent plasticity.
Genetic dissection of the permissive program for growth plasticity identifies the receptor protein tyrosine phosphatase (RPTP) Lar as a potential effector of BMP signaling

We next hypothesized that one or more of Mad's downstream effector genes may regulate activity-dependent NMJ growth. Several molecules have been extensively examined for their role in activity-dependent plasticity at the NMJ (Table 1), including the IgCAM Fasciclin-2 (Fas2), the adenylyl cyclase Rutabaga (Rut), and the transcriptional regulators AP-1 and CAMP-CREB (Zhong et al., 1992; Davis et al., 1996; Schuster et al., 1996a, b; Davis and Goodman, 1998; Sanyal et al., 2002, 2003; Zhong and $\mathrm{Wu}, 2004)$. We also evaluated a potential role for Neurexin, as its elevated expression expands the NMJ, whereas neurexin mutants show abnormal separations between the presynaptic and postsynaptic membranes, similar to wit (Li et al., 2007; Banovic et al., 2010). Last, we examined a role for the RPTP Lar because its level of expression correlates with the number of synaptic boutons (Kaufmann et al., 2002), as if Lar acts as a "gain controller" for NMJ growth.

We tested each of these candidate genes in combination with $\mathrm{Mad}^{1}$ to determine whether they could expand the NMJ in the absence of canonical BMP-dependent transcription. As previously reported, decreased Fas2 or increased cAMP or AP-1 levels expanded the NMJ when BMP signaling was intact (Table 1). Nevertheless, these growth-enhancing effects were blocked by Mad $^{1}$ expression (Table 1). Similarly, overexpression of Neurexin together with $\mathrm{Mad}^{1}$ produced a small NMJ (Table 1) $\left(\right.$ ELAV $>$ Neurexin $+\mathrm{Mad}^{1}-\mathrm{RU}$ vs ELAV $>$ Neurexin $+\mathrm{Mad}^{l}$ $+\mathrm{RU}, p<0.05 ; E L A V>\mathrm{Mad}^{1}$ vs ELAV $>$ Neurexin $+\mathrm{Mad}^{1}, p=$ 0.09). Thus, although these diverse molecules can influence NMJ expansion, in every case they depend on other genes downstream of the canonical BMP pathway to achieve their effects.

By contrast, neuronal expression of the RPTP Lar was sufficient to restore NMJ growth and plasticity despite $\mathrm{Mad}^{1}$ expression. As previously shown (Kaufmann et al., 2002), heteroallelic Lar mutations $\left(\operatorname{Lar}^{5.5} / \mathrm{Lar}^{13.2}\right)$ reduce synaptic size (see Fig. 8b, compare bars 1 and 3), whereas overexpression of full-length Lar had the opposite effect (control: $72 \pm 4$; Lar gain of function: $105 \pm 5 ; p=0.0002$ ). Neuronal overexpression of Lar fully rescued the effects of $\mathrm{Mad}^{1}$ expression (Table $1 ; p=0.24)$, whereas a phosphatase-dead form of Lar was less effective (Fig. $7 a, p=0.006$ ), indicating the partial restoration of NMJ growth despite dependence on Lar's phosphatase activity.

To further investigate the relationship between Mad and Lar during NMJ growth, we examined how mutations of each affected the expression of the other. We found that pMad immunofluorescence was present in Lar mutant motoneuron nuclei, showing that Lar function is not critically required for either Mad expression or its activation. We also found that the level of Lar transcript within the third instar CNS was unchanged in either wit mutants or after expression of $\mathrm{Mad}^{1}$, as assessed by $\mathrm{qPCR}$ (Fig. $7 b$ ). We next examined when Lar function is required during development: the phenocritical rescue of Lar mutants (Fig. $7 c$ ) shows that neither early (E,L1) nor late (L2,L3) expression alone is sufficient to restore NMJ growth in Lar mutants, indicating that unlike BMP mutants which have an early requirement for growth, Lar is required throughout development.

As might be expected for an effector of BMP-dependent synaptic plasticity, Lar is required for activity-dependent NMJ growth. The small synapses in Lar mutants were unaffected by eag $S h$ (Fig. $8 a, b$ ) or by high-temperature rearing (Fig. $8 b$, Lar vs eag $S h ;$ Lar, $p=0.21$; Lar vs $\left.\operatorname{Lar} 30^{\circ} \mathrm{C}, p=0.37\right)$. Presynaptic expres- 
Table 1. Genetic tests of NMJ growth and plasticity in the presence of Mad inhibition

\begin{tabular}{|c|c|c|c|c|}
\hline Gene/transgene & Protein function & Experimental test & NMJ boutons $(\mathrm{N})^{g}$ & Effect \\
\hline \multirow[t]{2}{*}{$\operatorname{Mad}^{1}$ (dominant negative transgene) } & \multirow[t]{2}{*}{ Canonical BMP signaling $^{a}$} & ELAV $>\operatorname{Mad}^{1}(-R U)$ & $87 \pm 6(8)$ & - \\
\hline & & $E L A V>\operatorname{Mad}^{1}(+R U)$ & $45 \pm 3^{*}(10)$ & $\downarrow$ \\
\hline \multirow[t]{4}{*}{ AP1 (Fos + Jun) } & \multirow[t]{4}{*}{ Immediate early transcription $^{b}$} & ELAV $>$ Fos, Jun $(-R U)$ & $75 \pm 6(6)$ & - \\
\hline & & ELAV $>$ Fos, Jun (+RU) & $109 \pm 3^{*}(6)$ & $\uparrow$ \\
\hline & & ELAV > Fos, Jun, $\operatorname{Mad}^{1}(-R U)$ & $77 \pm 4(6)$ & - \\
\hline & & ELAV $>$ Fos, Jun, $\operatorname{Mad}^{1}(+R U)$ & $50 \pm 2^{*}(6)$ & $\downarrow$ \\
\hline \multirow[t]{4}{*}{ Rutabaga ( $\mathrm{Ca}^{2+}$-dependent adenylyl cyclase) } & \multirow[t]{4}{*}{ CAMP signaling ${ }^{c}$} & ELAV > Rut $(-R U)$ & $82 \pm 2(6)$ & - \\
\hline & & ELAV $>$ Rut $(+R U)$ & $96 \pm 3^{*}(6)$ & $\uparrow$ \\
\hline & & ELAV $>$ Rut, $^{\operatorname{Mad}^{1}}(-\mathrm{RU})$ & $73 \pm 4(6)$ & 1 \\
\hline & & ELAV-GS $>$ Rut, $\operatorname{Mad}^{1}(+R U)$ & $51 \pm 2^{*}(6)$ & $\downarrow$ \\
\hline \multirow[t]{2}{*}{ Fasciclin 2 (IgCAM) } & \multirow[t]{2}{*}{ Synaptic adhesion ${ }^{d}$} & fas 2, ELAV $>\operatorname{Mad}^{1}(-\mathrm{RU})$ & $107 \pm 13^{*}(6)$ & $\uparrow$ \\
\hline & & fas2, ELAV $>\operatorname{Mad}^{1}(+\mathrm{RU})$ & $48 \pm 3^{*}(6)$ & $\downarrow$ \\
\hline \multirow[t]{2}{*}{ Neurexin } & \multirow[t]{2}{*}{ Synaptic adhesion ${ }^{e}$} & ELAV $>$ Neurexin, $\operatorname{Mad}^{1}(-R U)$ & $77 \pm 7(5)$ & - \\
\hline & & ELAV $>$ Neurexin, $\operatorname{Mad}^{1}(+R U)$ & $53 \pm 5^{*}(5)$ & $\downarrow$ \\
\hline \multirow[t]{2}{*}{ LAR } & \multirow[t]{2}{*}{ Receptor protein tyrosine phosphatase $e^{f}$} & $E L A V>\operatorname{Lar} \operatorname{Mad}^{1}(-R U)$ & $72 \pm 2(5)$ & - \\
\hline & & 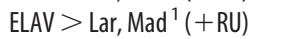 & $67 \pm 2$ (NS) (5) & - \\
\hline
\end{tabular}

${ }^{a}$ Mad signaling genotype: w; UAS-Mad ${ }^{1} /+$ : ELAV-GS-GAL4/+. RU, RU-486.

${ }^{b}$ AP-1 signaling genotype: w; UAS-Fos/+; UAS-Jun/ELAV-GS-GAL4 and w; UAS-Fos/UAS-Mad ${ }^{1}$; UAS-Jun/ELAV-GS-GAL4.

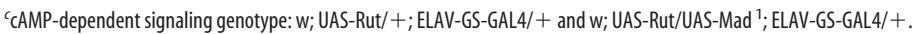

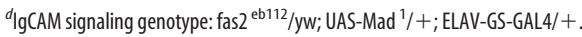

${ }^{e}$ Neurexin genotype: w; UAS-Mad ${ }^{1} /$ UAS-dnrxf1: ELAV-GS-GAL4/+.

'LAR genotype: w; UAS-Mad $11+$ : ELAV-GS-GAL4/UAS-Lar. The data show that coexpression of Lar with the Mad ${ }^{1}$ transgene restored normal NMJ size compared with ELAV $>$ Mad ${ }^{1}$ ( + RU), shown in the first row of the table.

${ }^{9} \mathrm{NMJ}$ size was scored on mfs 7 and 6 in segments A3 and A4, from N animals. Statistical comparisons were made between the overexpression conditions (Rut and AP- 1 alone or together with Mad ${ }^{1}$ ) and between the same genotypes raised with (+RU) and without RU ( $-R U)$. The loss of function fas 2 control data ( $-R U)$ was compared with the ELAV-GS $>$ Mad $^{1}$ control $(-R U)$ and with data collected with RU-486 induction.

${ }^{*} p<0.005$. NS, Not significant.

sion of Lar in an eag Sh, ELAV> $\mathrm{Mad}^{1}$ background also restored activity-dependent NMJ expansion (Fig. 8c). The synapses of these animals were similar in size to those of eag $\operatorname{Sh}(p=0.07)$ and were significantly larger than WT NMJs coexpressing $\mathrm{Mad}^{1}$ and Lar $\left(p<10^{-5}\right)$. In conclusion, the NMJ growth defects associated with disruption of Mad signaling can be rescued with elevated Lar expression in presynaptic motoneurons. This indicates that Lar acts either in parallel to BMP signaling or that BMP signaling regulates Lar function in a transcriptionindependent manner.

\section{Mad signaling throughout development influences NMJ physiology}

Despite our observation that BMP signaling is necessary and sufficient for NMJ growth only during L1, levels of pMad within motoneuron nuclei remain high throughout larval life (Fig. 2c) (Collins et al., 2006; Wang et al., 2007). To address potential roles for nuclear pMad during the later stages of development, we characterized when Mad signaling regulates NMJ physiology. BMP signaling mutations have striking effects on neurotransmission in addition to defects in synaptic growth. BMP mutants have smaller EJPs from both the small $\left(\mathrm{I}_{\mathrm{S}}\right)$ and large $\left(\mathrm{I}_{\mathrm{B}}\right)$ type I boutons and a reduced quantal content, and nearly all also show a lower frequency of spontaneous mEJPs (Aberle et al., 2002; Marqués et al., 2002; McCabe et al., 2003).

We first confirmed that presynaptic expression of $\mathrm{Mad}^{1}$ phenocopied the physiological defects observed in mad mutants (McCabe et al., 2004). Using the GeneSwitch system and RU-486 exposure to express $\mathrm{Mad}^{1}$ throughout development, we observed a decrease in EJP size in $\mathrm{mf} 12$, without an alteration in $\mathrm{mEJP}$ amplitude, consistent with a reduced quantal content (Fig. 9, compare the black and white bars). When $\mathrm{Mad}^{1}$ was expressed during the early critical period (E and L1) but not afterward (L2 and L3), EJPs were intermediate in size (Fig. 9a), mEJP amplitudes were unchanged (Fig. $9 c ; \mathrm{mf} 12, \mathrm{mV} ; E L A V>\mathrm{Mad}^{1}-\mathrm{RU}$ : $0.75 \pm 0.20, E L A V>M^{1}+\mathrm{RU}$ : $0.64 \pm 0.19, E L A V>\mathrm{Mad}^{1}$
$+\mathrm{RU}(\mathrm{E}, \mathrm{L} 1): 0.69 \pm 0.19)$, and the quantal content was significantly reduced for the type $\mathrm{I}_{\mathrm{B}}$ synapse (Fig. 9d). Animals with $\mathrm{Mad}^{1}$ induction only during the E and L1 stages had small-sized NMJs (Fig. 1b, bar 7), yet despite this had EJP amplitudes and the frequencies of spontaneous release that were larger than in animals with $\mathrm{Mad}^{1}$ induced throughout larval development. The absence of $\mathrm{Mad}^{1}$ induction during L2 and L3 appears to have enabled these physiological properties to recover to the WT level, as if Mad-dependent signaling effectively promotes physiological function at stages after the L1-sensitive period for NMJ growth. To test this, we induced $\mathrm{Mad}^{1}$ during L2 and L3 and examined synaptic physiology at the NMJs of control and experimental animals that had comparable numbers of boutons ( $\mathrm{mf} 12$; $E L A V>\mathrm{Mad}^{1}-\mathrm{RU}: 120.9 \pm 9.3 ; E L A V>\mathrm{Mad}^{1}+\mathrm{RU}$ (L2,L3): $119.3 \pm 6.8)$. Significantly, the late induction of $\mathrm{Mad}^{1}$ reduced the amplitude of evoked EJPs and the frequency of mEJPs (Fig. 10). EJPs from both $I_{B}$ and $I_{S}$ boutons on $\mathrm{mf} 12$ were significantly reduced compared with EJPs in controls without RU-486 exposure. As the amplitude of mEJPs remained unaltered (Fig. 10d; $\mathrm{mV} ; E L A V>\mathrm{Mad}^{1}-\mathrm{RU}: 0.75 \pm 0.20 ; E L A V>\mathrm{Mad}^{1}$ $+\mathrm{RU}(\mathrm{L} 2, \mathrm{~L} 3): 0.65 \pm 0.20$ ), these results again indicated a reduction in quantal content for the $\mathrm{I}_{\mathrm{B}}$ synapse (Fig. 10e). Thus, BMP signaling is required throughout development for normal synaptic physiology, in contrast to the early requirement of BMP signaling for NMJ growth.

The decrease in mEJP frequency and reduction in quantal content by $\mathrm{Mad}^{1}$ expression might be due to active zone defects. wit, $g b b$, and mad mutations show fewer release sites per bouton, but these active zones are abnormally enlarged (Aberle et al., 2002; Marqués et al., 2002; McCabe et al., 2003, 2004). We examined putative active zones by visualizing Bruchpilot (Brp), an ELKS/CAST/ERC active zone-associated protein (Wagh et al., 2006) within the terminal type $I_{B}$ boutons on $\mathrm{mf} 12$. Brp labeling appeared as numerous distinct, fluorescent punctae. Induction of Mad ${ }^{1}$ late in larval development (L2 and L3) reduced the number 
a

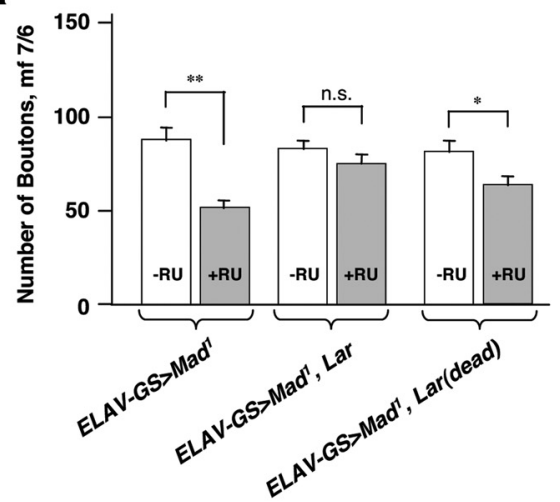

b

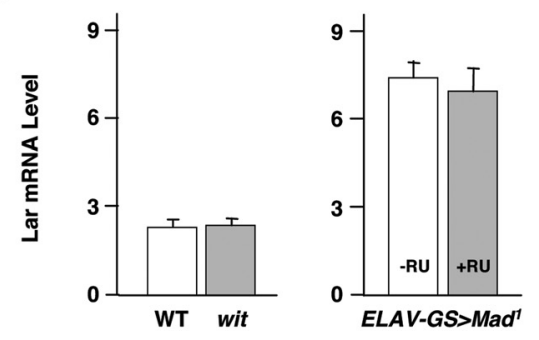

C

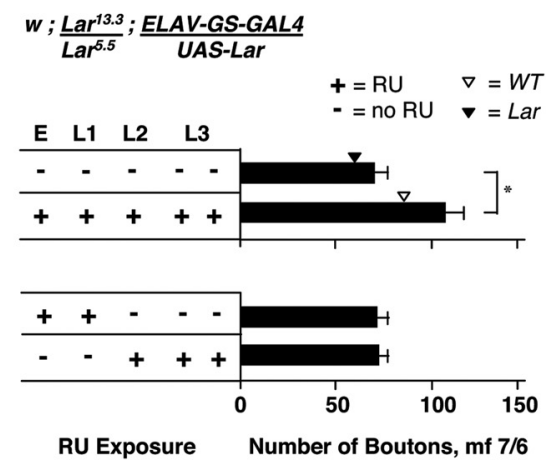

Figure 7. The receptor protein tyrosine phosphatase Lar rescues the growth defects caused by Mad ${ }^{1}$, but Lar expression is independent of BMP signaling. $\boldsymbol{a}$, Increased expression of Lar restores normal NMJ size despite the inhibition of Mad signaling. The number of boutons on $\mathrm{mf}$ $7 / 6$ in third instar larvae are shown. RU-486 induction was throughout development. The first two bars compare the number of synaptic boutons with or without the induced expression of the Mad ${ }^{1}$ transgene in neurons (ELAV $>$ Mad $^{7} ;$ w; UAS-Mad $\left.{ }^{1} /+; E L A V-G S-G A L 4 /+\right)$. The next two bars compare bouton numbers with or without induction of both $\operatorname{Mad}^{1}$ and Lar (ELAV > Mad $^{7}$, Lar; w; UAS-Mad ${ }^{1}$ /+; ELAV-GS-GAL4/UAS-Lar). Induced expression of Lar restores NMJ size despite the presence of Mad $^{1}$ to suppress BMP signaling. The next two bars show the same experiment done with a phosphatase-dead version of $\operatorname{Lar}$ (dead) (ELAV> Mad ${ }^{1}$, Lar(dead); $w$; UAS-Mad'/+; ELAV-GS-GAL4/UAS-LarC1638S+(1929S). The partial rescue suggests that Lar localization and its catalytic activity are both involved in the rescue of the NMJ growth phenotype. $\boldsymbol{b}$, qPCR analysis of Lar transcripts isolated from the third instar CNS of WT, wit (wit ${ }^{A 12}$ ) $\left.w_{i t}^{B 11}\right)$, and ELAV-GS > Mad ${ }^{1}\left(y w\right.$; UAS-Mad ${ }^{1}$; ELAV-GS-GAL4) reared in the presence $(R U+)$ and absence $(-R U)$ of RU-486. Lar transcript levels remain unaffected by either wit mutations or by the induced expression of the $\mathrm{Mad}^{1}$ transgene. $c$, Bouton counts on $\mathrm{mf}$ 7 and 6 in Lar mutant animals rescued by RU-486 induced expression of Lar at different stages of development. The first bar represents NMJ size in the absence of Lar induction. The black arrowhead indicates the average bouton count for the $\mathrm{Lar}^{13.3} / \mathrm{Lar}^{5.5}$ mutant. The second bar represents the effect of inducing the expression of Lar throughout development, which strongly rescues the growth defects in Lar mutants. White arrowhead indicates the average bouton count for WT NMJs. The third and fourth bars show that induction of $L a r$ in neither early stages ( $E$ and $L 1$, bar 3 ) nor late stages ( $L 2$ and L3, bar 4) could rescue the Lar mutations. ${ }^{*} p<0.05 .{ }^{* *} p<0.005$. n.s., Not significant. a
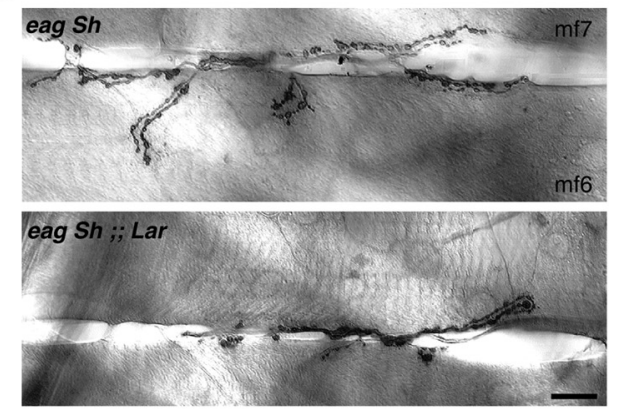

b
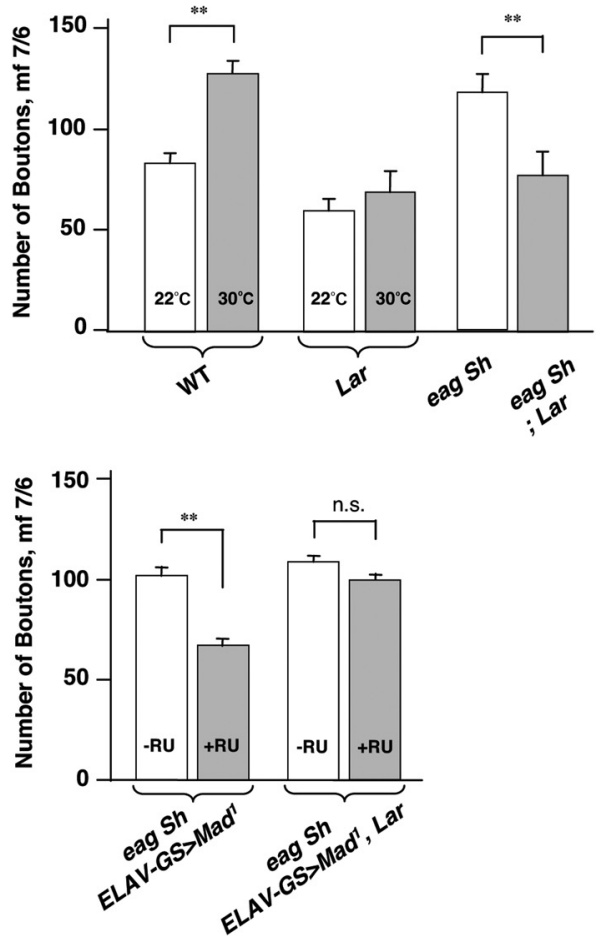

Figure 8. Lar is required for synaptic plasticity at the Drosophila neuromuscular junc-

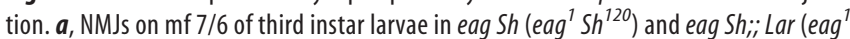
$S h^{120} / Y ; L^{5}{ }^{5.5} / L_{a r}{ }^{13.2}$ ) triple mutants. Scale bar, $25 \mu \mathrm{m}$. $\boldsymbol{b}$, NMJ expansion resulting from elevated temperature rearing or eag $S h$ hyperactivity depends on Lar function. The number of boutons in WT and $\operatorname{Lar}\left(\mathrm{Lar}^{5.5} / \mathrm{Lar}^{13.2}\right)$ animals reared at $22^{\circ} \mathrm{C}$ and $30^{\circ} \mathrm{C}$, and in hyperactive eag $S h$ and eag $S h ; ;$ Lar animals. $c$, The number of boutons in eag $S h$ animals expressing Mad $^{1}$ (eag Sh, ELAV > Mad ${ }^{1} ;$ eag $^{1}$ Sh $^{120}$; UAS-Mad ${ }^{1} /+;$ ELAV-GS-GAL4/+) and coexpressing Mad ${ }^{1}$ and Lar (eag Sh, ELAV > Mad ${ }^{1}$, Lar; $_{\text {eag }}{ }^{1}$ Sh $^{120} ;$ UAS-Mad $^{1} /+$; ELAV-GS-GAL4/UAS-Lar) with (+RU) and without (-RU) RU-486. Lar function is sufficient to permit synaptic expansion in the presence of elevated NMJ activity, even with suppressed BMP signaling due to coexpression of $\mathrm{Mad}^{1} .{ }^{* *} p<0.005$. n.s., Not significant.

and increased the size of these punctae (Fig. 10f,g). A defect in active zone size has also been documented in Lar mutants (Kaufmann et al., 2002), suggesting that Lar may be involved in BMP-dependent regulation of neurotransmission. However, coexpression of $\mathrm{Mad}^{1}$ and Lar reduced the amplitude of synaptic potentials similar to those of $\mathrm{Mad}^{1}$ alone $(\mathrm{mf} 6$, mean \pm SEM, $\mathrm{mV} ; \mathrm{I}_{\mathrm{B}}$ synapse; ELAV $>\mathrm{Mad}^{1}+\mathrm{RU}: 12.32 \pm 0.39 ; E L A V>$ $\mathrm{Mad}^{1}+$ Lar +RU: $12.86 \pm 0.60, p=0.49 ; \mathrm{I}_{\mathrm{S}+\mathrm{B}} ; E L A V>\mathrm{Mad}^{1}$ $+\mathrm{RU}: 22.01 \pm 0.5 ; E L A V>\mathrm{Mad}^{1}+$ Lar $+\mathrm{RU}: 22.69 \pm 1.22, p=$ $0.62 ; n \geq 6)$. The frequency of spontaneous mEJPs was also not rescued (mean $\pm \mathrm{SEM}, \mathrm{Hz} ; E L A V>\mathrm{Mad}^{1}+\mathrm{RU}: 1.03 \pm 0.20$ $\left.E L A V>\mathrm{Mad}^{1}+L a r+R U: 1.18 \pm 0.20, p=0.61\right)$. Our results 
a
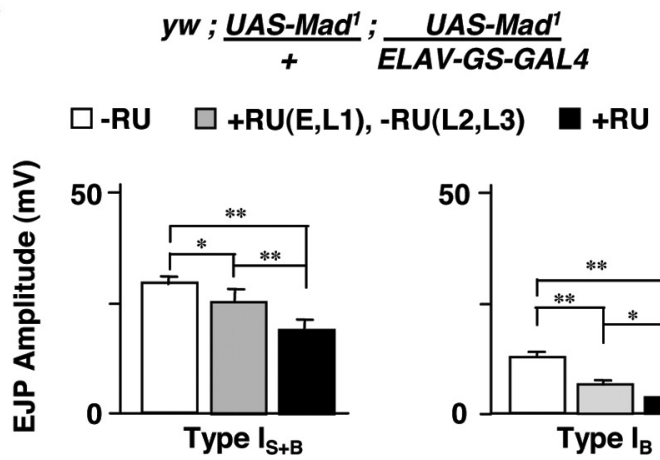

b

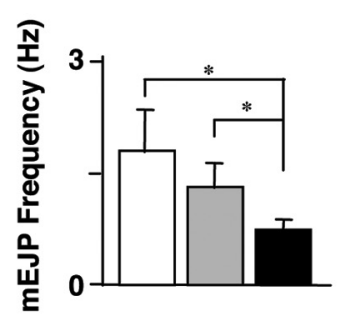

C

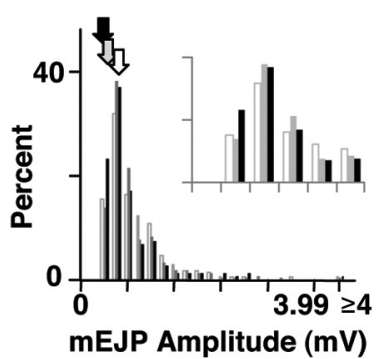

d

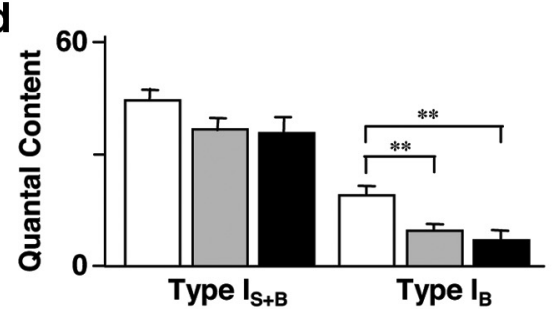

Figure 9. Canonical BMP signaling throughout larval development regulates neurotransmitter release at the NMJ. $\boldsymbol{a}$, EJP amplitudes from type $I_{S+B}$ and $I_{B}$ synapses in $y w$; UAS$\mathrm{Mad}^{1} /+$; UAS-Mad /ELAV-GS-GAL4 animals with induced expression of Mad ${ }^{1}$. Black bars, RU-486 induced expression throughout embryonic and larval development: + RU. Gray bars, induced expression only during $E$ and $L 1$, but not $L 2$ and $L 3:+R U(E, L 1),-R U(L 2, L 3)$. White bars, no RU-486 induction: $-\mathrm{RU} . n=7$ larvae for $+\mathrm{RU}, n=6$ for $+\mathrm{RU}(\mathrm{E}, \mathrm{L} 1),-\mathrm{RU}(\mathrm{L} 2, \mathrm{~L} 3)$, and $n=7$ for + RU. $\boldsymbol{b}$, The frequency of spontaneous mEJPs resulting from the induced expression of $\mathrm{Mad}^{1}$, a s indicated in $\boldsymbol{a} ; n=7$ larvae for $+\mathrm{RU}, n=7$ for $+\mathrm{RU}(\mathrm{E}, \mathrm{L} 1),-\mathrm{RU}(\mathrm{L} 2, \mathrm{~L} 3)$, and $n=7$ for + RU. c, Amplitude distribution of mEJPs resulting from the induced expression of $\mathrm{Mad}^{1}$, as indicated in $\boldsymbol{a}$. Bin size, $0.2 \mathrm{mV}$. A separate bin is shown for the rare cases of amplitudes $\geq 4.0 \mathrm{mV}$. Arrows indicate the mean $\mathrm{mEJP}$ amplitude for each condition, which did not differ significantly. The first 5 bins are also shown at high magnification (inset). $\boldsymbol{d}$, Quantal content computed for both the $I_{S+B}$ terminals and for the $I_{B}$ terminal by taking the ratio of the mean EJP amplitude/mean $\mathrm{mEJP}$ amplitude.

therefore support the idea that Mad signals throughout development to influence neurotransmission at the NMJ and that the Lar RPTP may not be integral for Mad's effects on synaptic physiology.

\section{Discussion}

We have investigated how retrograde BMP signaling by Gbb, Wit, and Mad influences the development of the Drosophila NMJ. Our experiments examined the timing of retrograde signaling and the relationship between BMP signaling and the activity-dependent modulation of NMJ development. The results indicate that an early and transient period of BMP signaling, acting through Mad, activates key developmental programs necessary for synapse maturation. Transcriptional regulation by Mad in the first larval instar $(\mathrm{L} 1,24 \mathrm{~h})$ is necessary and sufficient for robust NMJ growth during the second (L2) and third (L3) instars (72 h). Mad signal- ing during L1 also allows activity to enhance the growth process. By contrast, Mad signaling in L1 through L3 is required for normal active zone morphology and the developmental increase in quantal content. Our results therefore indicate that retrograde BMP signaling "gates" NMJ development and plasticity by initiating two genetically separable programs for growth and physiology.

\section{Retrograde BMP signaling may signal successful NMJ formation to the motoneuron nucleus}

In the absence of retrograde BMP signaling, the NMJ shows only residual growth, forming weak connections that are insensitive to activity-dependent modulation. BMP signaling mutations do not disrupt axonal guidance, target selection, or the initiation of synaptogenesis. They instead have profound effects on later aspects of synaptic development, affecting NMJ expansion and bouton stabilization (Aberle et al., 2002; Marqués et al., 2002; McCabe et al., 2003, 2004; Rawson et al., 2003; Eaton and Davis, 2005; Goold and Davis, 2007). We found that expression of $\mathrm{Mad}^{1}$, the protein encoded by the strong dominant-negative $\mathrm{mad}^{1}$ allele, phenocopies BMP signaling mutants (see Materials and Methods), affecting both NMJ growth (Fig. 1b, bars 1 and 2) and physiology (Fig. 9). By driving $\mathrm{Mad}^{1}$ expression at various times during development, we found that Mad-dependent signaling during L1 is both necessary and sufficient for subsequent NMJ growth. Our results are consistent with an L1 critical period for BMP signaling. Inducing $\mathrm{Mad}^{1}$ expression at all times except L1 produced a WTsized NMJ, whereas induction only during L1 reduced NMJ size to that seen in mad mutants (Fig. 1, bars 9 and 10). The genetic rescue of $g b b$ and wit mutants also revealed the importance of the retrograde BMP pathway signaling during embryogenesis and L1 (Figs. $2 a$ and 3). The timing of retrograde BMP signaling, after synaptogenesis yet before growth commences, suggests a model where the muscle uses BMP signaling to inform the motoneuron nucleus of a successfully formed synapse, activating subsequent growth and plasticity programs. The exact timing of this critical period, however, requires knowing when the $\mathrm{Mad}^{1}$ transgene inhibits transcription of Mad's major effectors of NMJ growth, which are unknown. Our data indicate that a $24 \mathrm{~h}$ exposure to RU-486 during L1 expresses enough $\mathrm{Mad}^{1}$ to suppress NMJ growth (Fig. 1, bar 10). It also suggests that the perdurance of the dominant negative plus the time needed for its activation must be less than $24 \mathrm{~h}$, as expression during embryogenesis, L2, and L3 led to NMJs that were nearly WT in size (Fig. 1, bar 9). Therefore, although the critical period may be shifted later in development than our data indicate, it is likely to begin as early as $5 \mathrm{~h}$ after the onset of L1.

Our data provide an entrance into the mechanisms regulating the critical period. Based on its timing between the embryonic and L2 stages, it is possible that molting hormones influence Mad activity (Miller et al., 2012). Recent work also indicates that anterograde activin signaling induces Gbb expression in body wall muscles (Ellis et al., 2010), whereas postsynaptic dCIP4 signaling (Drosophila Cdc42 Interacting Protein 4) and the activity of dRich, a conserved Cdc 42-selective guanosine triphosphataseactivating protein, inhibits Gbb secretion from these muscles (Nahm et al., 2010a, b). Furthermore, the secretion of a TGF- $\beta$ ligand (Maverick) from peripheral glia strongly regulates $\mathrm{Gbb}$ signaling from the postsynaptic muscle, affecting both pMad levels within motoneurons and NMJ growth (Fuentes-Medel et al., 2012). It would therefore be interesting to perform phenocritical analyses on activin, dCIP4, dRich, and Maverick and to address whether postsynaptic depolarization influences the activity of dCIP4 
or dRich. Our genetic interaction experiments found no evidence to suggest that moderate increases in BMP signaling modulate the final size of the NMJ or synergize with presynaptic activity. Our findings of an early critical period for NMJ growth differ slightly from a previous study, which overexpressed an inhibitory SMAD (Goold and Davis, 2007). In an effort to reconcile our results with these earlier data, we transiently expressed Dad during L1 but found no alteration in NMJ size (data not shown), perhaps resulting from different mechanisms of BMP pathway inhibition.

\section{Separable Mad-dependent programs} control synaptic growth and physiology An unexpected result from our study is that the early BMP signal is necessary and sufficient for subsequent growth and structural plasticity, but not for synaptic function. In the absence of later BMP signaling, the NMJ grows to its structurally normal size but has reduced neurotransmission. The later requirement for BMP signaling is consistent with the observation that pMad levels remain high in motoneuron nuclei throughout larval development. In the absence of continual Mad activity, the number of active zones is reduced and their size is aberrantly enlarged (Fig. 10). The separable roles of BMP signaling for NMJ growth and function are also consistent with the distinct actions of the two known targets of retrograde BMP signaling in motoneurons, Trio and Twit (Ball et al., 2010; Kim and Marqués, 2012).

We do not know whether the active zone phenotype arising from the loss of BMP signaling late in development results from defects in the formation or the maintenance of these structures. The active zone protein dSyd and the Teneurin-a adhesion molecule are potentially involved in Mad's physiological program, as their loss causes physiological and ultrastructural phenotypes that overlap with those of BMP mutants (Owald et al., 2010; Mosca et al., 2012). Future studies of how Mad simultaneously and separately regulates NMJ growth and physiology could lead to a deeper understanding of how dSyd and Teneurin-a might act dowstream of Mad. The separable downstream effects of Mad on growth versus physiology may depend on post-translational modifications that can occur at the linker between the MH1 and MH2 domains, changes that can affect the affinity of Mad's binding partners (Chen et al., 2006; Knockaert et al., 2006; Blitz and Cho, 2009). Unfortunately, Mad's noncanonical binding partners in motoneurons are entirely uncharacterized.

Activity-dependent synaptic plasticity: BMP signaling and the Lar phosphatase

Elevated action potential firing in motoneurons resulting from the loss of repolarizing $\mathrm{K}^{+}$channels or by hightemperature rearing substantially enhances NMJ growth and b

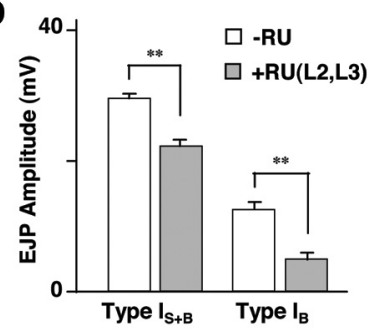

$\mathbf{e}$

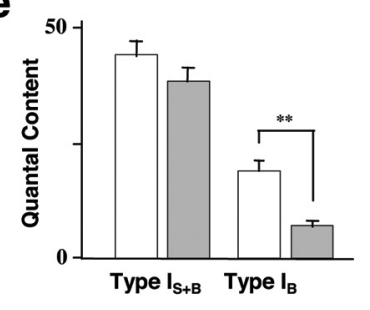

g

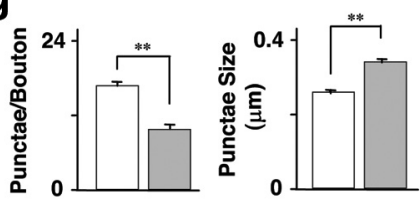

Figure 10. Mad signaling during late larval stages is required for normal neurotransmission and active zone morphology. $\boldsymbol{a}$,

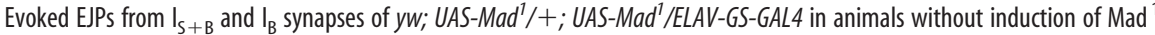
作 ( 列 ars as multiple punctae within synaptic boutons. Shown are the terminal two $I_{B}$ boutons from a mf 12 NMJ branch, from a the terminal two $I_{B}$ boutons of $m f 12$ NMJ branches of $-R U$ and $+R U(L 2, L 3)$ third instar larvae, as well as the average diameter of the labeled punctae. ${ }^{* *} p<0.005$.

synaptic transmission (Budnik et al., 1990; Davis et al., 1996; Schuster et al., 1996b; Zhong and Wu, 2004; Mosca et al., 2005). Mutations affecting the BMP signaling pathway block this plasticity (Fig. 4) without suppressing presynaptic hyperactivity (Fig. 5). Our results indicate that retrograde BMP signaling allows motoneuron growth to be responsive to increased levels of activity. Indeed, the level of excitability during Mad's critical period for growth strongly affected synaptic size in mature larvae (compare Fig. 1, bar 9 with Fig. $6 c$, bar 3 ). Understanding how this early activity engages BMPdependent programs could be very insightful given that cAMP, AP-1, and Fas-2 signaling failed to rescue the effects of Mad $^{1}$ expression (Table 1 ).

Instead, the receptor protein tyrosine phosphatase Lar rescued both normal and activity-dependent NMJ growth (Figs. $7 a$ and $8 c$ ), and Lar was required for activity-dependent developmental plasticity (Fig. $8 a, b$ ). Lar family members are essential, well-conserved regulators of synaptogenesis from worms and flies to mammals (Van Vactor et al., 2006). Despite the prior identification of extracellular ligands for Lar family RPTPs, there has been no significant insight into the temporal regulation of Lar signaling during synaptogenesis in any system. Current evidence suggests that the Lar pathway regulates cytoskeletal assembly and active zone formation (Kaufmann 
et al., 2002; Johnson and Van Vactor, 2003; Johnson et al., 2006) while antagonizing the activity of the highly conserved Abelson (Abl) tyrosine kinase (Wills et al., 1999). At the larval stage, Abl negatively regulates NMJ size (Lin et al., 2009) and $a b l$ mutations have phenotypes reciprocal to those of Lar. Lar may relieve the growth-inhibitory action of $\mathrm{Abl}$, promoting synaptic expansion in response to elevated activity or postsynaptic growth. Lar acts via the actin-modulating protein Ena for NMJ growth (D.L.V.V., personal communication), whereas Trio and Lar regulate growth and the presynaptic cytoskeleton by interacting with Diaphanous, a member of the formin family of proteins (Pawson et al., 2008). As Trio levels are reduced in BMP mutants and the expression of Trio only partially rescues NMJ growth (Ball et al., 2010), it is possible that Ena or Diaphanous act independently of Mad signaling.

In the absence of BMP signaling, the small NMJs can be genetically rescued by increased expression of Lar. This suggests that reduced BMP signaling in some fashion reduces Lar activity or function at the NMJ. Our qPCR analyses show that Lar transcript levels remain normal despite reduced pMad activity (Fig. 7b), leaving open the possibility that post-transcriptional mechanisms reduce Lar expression, NMJ localization, or activity, either by changes to the receptor itself, to Lar's binding partners (for e.g., Liprins), or to the heparin sulfate proteoglycan ligands. Our observations support a model where retrograde BMP signaling allows synaptic growth to be modulated by neural activity, with Lar acting as the downstream "gain controller" to establish the specific level of synaptic efficacy. In this model, postsynaptic BMP release initiates competence of the presynaptic terminal to respond to the matrix via Lar. Lar's heparin sulfate proteoglycan ligands and its anchoring proteins (Liprins) (Kaufmann et al., 2002; Astigarraga et al., 2010) might then provide spatial information or couple Lar function to synaptic activity. Heparin sulfate proteoglycans play important roles during critical periods (Hensch, 2004), and they modulate the signaling of BMPs, Wnts, and fibroblast growth factors (Van Vactor et al., 2006). It is therefore possible that the extracellular matrix provides a key integrator that coordinates multiple transsynaptic signals in a developmental and activity-dependent manner (Dani et al., 2012).

\section{References}

(2002) wishful thinking encodes a BMP type II receptor that regulates synaptic growth in Drosophila. Neuron 33:545-558. CrossRef Medline

Allan DW, St Pierre SE, Miguel-Aliaga I, Thor S (2003) Specification of neuropeptide cell identity by the integration of retrograde BMP signaling and a combinatorial transcription factor code. Cell 113:73-86. CrossRef Medline

Ashley J, Packard M, Ataman B, Budnik V (2005) Fasciclin II signals new synapse formation through amyloid precursor protein and the scaffolding protein dX11/Mint. J Neurosci 25:5943-5955. CrossRef Medline

Astigarraga S, Hofmeyer K, Farajian R, Treisman JE (2010) Three Drosophila liprins interact to control synapse formation. J Neurosci 30:1535815368. CrossRef Medline

Augsburger A, Schuchardt A, Hoskins S, Dodd J, Butler S (1999) BMPs as mediators of roof plate repulsion of commissural neurons. Neuron 24: 127-141. CrossRef Medline

Baines RA (2004) Synaptic strengthening mediated by bone morphogenetic protein-dependent retrograde signaling in the Drosophila CNS. J Neurosci 24:6904-6911. CrossRef Medline

Ball RW, Warren-Paquin M, Tsurudome K, Liao EH, Elazzouzi F, Cavanagh C, An BS, Wang TT, White JH, Haghighi AP (2010) Retrograde BMP signaling controls synaptic growth at the NMJ by regulating trio expression in motor neurons. Neuron 66:536-549. CrossRef Medline

Banovic D, Khorramshahi O, Owald D, Wichmann C, Riedt T, Fouquet W, Tian R, Sigrist SJ, Aberle H (2010) Drosophila neuroligin 1 promotes growth and postsynaptic differentiation at glutamatergic neuromuscular junctions. Neuron 66:724-738. CrossRef Medline
Blitz IL, Cho KW (2009) Finding partners: how BMPs select their targets. Dev Dyn 238:1321-1331. CrossRef Medline

Broadie KS, Bate M (1993) Development of the embryonic neuromuscular synapse of Drosophila melanogaster. J Neurosci 13:144-166. Medline

Budnik V, Zhong Y, Wu CF (1990) Morphological plasticity of motor axons in Drosophila mutants with altered excitability. J Neurosci 10:3754-3768. Medline

Chen HB, Shen J, Ip YT, Xu L (2006) Identification of phosphatases for Smad in the BMP/DPP pathway. Genes Dev 20:648-653. CrossRef Medline

Cheung US, Shayan AJ, Boulianne GL, Atwood HL (1999) Drosophila larval neuromuscular junction's responses to reduction of cAMP in the nervous system. J Neurobiol 40:1-13. CrossRef Medline

Collins CA, Wairkar YP, Johnson SL, DiAntonio A (2006) Highwire restrains synaptic growth by attenuating a MAP kinase signal. Neuron 51: 57-69. CrossRef Medline

Dani N, Nahm M, Lee S, Broadie K (2012) A targeted glycan-related gene screen reveals heparan sulfate proteoglycan sulfation regulates WNT and BMP trans-synaptic signaling. PLoS Genet 8:e1003031. CrossRef Medline

Davis GW, Goodman CS (1998) Synapse-specific control of synaptic efficacy at the terminals of a single neuron. Nature 392:82-86. CrossRef Medline

Davis GW, Schuster CM, Goodman CS (1996) Genetic dissection of structural and functional components of synaptic plasticity: III. CREB is necessary for presynaptic functional plasticity. Neuron 17:669-679. CrossRef Medline

Eade KT, Allan DW (2009) Neuronal phenotype in the mature nervous system is maintained by persistent retrograde bone morphogenetic protein signaling. J Neurosci 29:3852-3864. CrossRef Medline

Eaton BA, Davis GW (2005) LIM Kinasel controls synaptic stability downstream of the type II BMP receptor. Neuron 47:695-708. CrossRef Medline

Ellis JE, Parker L, Cho J, Arora K (2010) Activin signaling functions upstream of Gbb to regulate synaptic growth at the Drosophila neuromuscular junction. Dev Biol 342:121-133. CrossRef Medline

Fuentes-Medel Y, Ashley J, Barria R, Maloney R, Freeman M, Budnik V (2012) Integration of a retrograde signal during synapse formation by glia-secreted TGF- $\beta$ ligand. Curr Biol 22:1831-1838. CrossRef Medline

Ganetzky B, Wu CF (1982) Drosophila mutants with opposing effects on nerve excitability: genetic and spatial interactions in repetitive firing. J Neurophysiol 47:501-514. Medline

Ganetzky B, Wu CF (1983) Neurogenetic analysis of potassium currents in Drosophila: synergistic effects on neuromuscular transmission in double mutants. J Neurogenet 1:17-28. CrossRef Medline

Goold CP, Davis GW (2007) The BMP ligand Gbb gates the expression of synaptic homeostasis independent of synaptic growth control. Neuron 56:109-123. CrossRef Medline

Haerry TE, Khalsa O, O'Connor MB, Wharton KA (1998) Synergistic signaling by two BMP ligands through the SAX and TKV receptors controls wing growth and patterning in Drosophila. Development 125:3977-3987. Medline

Hensch TK (2004) Critical period regulation. Annu Rev Neurosci 27:549_ 579. CrossRef Medline

Johnson KG, Van Vactor D (2003) Receptor protein tyrosine phosphatases in nervous system development. Physiol Rev 83:1-24. CrossRef Medline

Johnson KG, Tenney AP, Ghose A, Duckworth AM, Higashi ME, Parfitt K, Marcu O, Heslip TR, Marsh JL, Schwarz TL, Flanagan JG, Van Vactor D (2006) The HSPGs Syndecan and Dallylike bind the receptor phosphatase LAR and exert distinct effects on synaptic development. Neuron 49:517-531. CrossRef Medline

Kaufmann N, DeProto J, Ranjan R, Wan H, Van Vactor D (2002) Drosophila liprin- $\alpha$ and the receptor phosphatase Dlar control synapse morphogenesis. Neuron 34:27-38. CrossRef Medline

Keshishian H, Kim YS (2004) Orchestrating development and function: retrograde BMP signaling in the Drosophila nervous system. Trends Neurosci 27:143-147. CrossRef Medline

Keshishian H, Chiba A, Chang TN, Halfon MS, Harkins EW, Jarecki J, Wang L, Anderson M, Cash S, Halpern ME (1993) Cellular mechanisms governing synaptic development in Drosophila melanogaster. J Neurobiol 24:757-787. CrossRef Medline

Kim NC, Marqués G (2012) The Ly6 neurotoxin-like molecule target of wit 
regulates spontaneous neurotransmitter release at the developing neuromuscular junction in Drosophila. Dev Neurobiol 72:1541-1558. CrossRef Medline

Knockaert M, Sapkota G, Alarcón C, Massagué J, Brivanlou AH (2006) Unique players in the BMP pathway: small C-terminal domain phosphatases dephosphorylate Smad1 to attenuate BMP signaling. Proc Natl Acad Sci U S A 103:11940-11945. CrossRef Medline

Li J, Ashley J, Budnik V, Bhat MA (2007) Crucial role of Drosophila neurexin in proper active zone apposition to postsynaptic densities, synaptic growth, and synaptic transmission. Neuron 55:741-755. CrossRef Medline

Lin TY, Huang CH, Kao HH, Liou GG, Yeh SR, Cheng CM, Chen MH, Pan RL, Juang JL (2009) Abi plays an opposing role to Abl in Drosophila axonogenesis and synaptogenesis. Development 136:3099-3107. CrossRef Medline

Livak KJ, Schmittgen TD (2001) Analysis of relative gene expression data using real-time quantitative PCR and the 2(-Delta Delta C(T)) Method. Methods 25:402-408. CrossRef Medline

Marqués G (2005) Morphogens and synaptogenesis in Drosophila. J Neurobiol 64:417-434. CrossRef Medline

Marqués G, Bao H, Haerry TE, Shimell MJ, Duchek P, Zhang B, O'Connor MB (2002) The Drosophila BMP type II receptor Wishful Thinking regulates neuromuscular synapse morphology and function. Neuron 33: 529-543. CrossRef Medline

McCabe BD, Marqués G, Haghighi AP, Fetter RD, Crotty ML, Haerry TE, Goodman CS, O'Connor MB (2003) The BMP homolog Gbb provides a retrograde signal that regulates synaptic growth at the Drosophila neuromuscular junction. Neuron 39:241-254. CrossRef Medline

McCabe BD, Hom S, Aberle H, Fetter RD, Marqués G, Haerry TE, Wan H, O'Connor MB, Goodman CS, Haghighi AP (2004) Highwire regulates presynaptic BMP signaling essential for synaptic growth. Neuron 41:891905. CrossRef Medline

McGuire SE, Le PT, Osborn AJ, Matsumoto K, Davis RL (2003) Spatiotemporal rescue of memory dysfunction in Drosophila. Science 302:17651768. CrossRef Medline

McGuire SE, Mao Z, Davis RL (2004) Spatiotemporal gene expression targeting with the TARGET and gene-switch systems in Drosophila. Sci STKE 2004:pl6. CrossRef Medline

Miller DL, Ballard SL, Ganetzky B (2012) Analysis of synaptic growth and function in Drosophila with an extended larval stage. J Neurosci 32: 13776-13786. CrossRef Medline

Ming JE, Elkan M, Tang K, Golden JA (2002) Type I bone morphogenetic protein receptors are expressed on cerebellar granular neurons and a constitutively active form of the type IA receptor induces cerebellar abnormalities. Neuroscience 114:849-857. CrossRef Medline

Mosca TJ, Carrillo RA, White BH, Keshishian H (2005) Dissection of synaptic excitability phenotypes using a dominant-negative Shaker $\mathrm{K}+$ channel subunit. Proc Natl Acad Sci U S A 102:3477-3482. CrossRef Medline

Mosca TJ, Hong W, Dani VS, Favaloro V, Luo L (2012) Trans-synaptic Teneurin signalling in neuromuscular synapse organization and target choice. Nature 484:237-241. CrossRef Medline

Nahm M, Long AA, Paik SK, Kim S, Bae YC, Broadie K, Lee S (2010a) The $\mathrm{Cdc} 42$-selective GAP rich regulates postsynaptic development and retrograde BMP transsynaptic signaling. J Cell Biol 191:661-675. CrossRef Medline

Nahm M, Kim S, Paik SK, Lee M, Lee S, Lee ZH, Kim J, Lee D, Bae YC, Lee S (2010b) dCIP4 (Drosophila Cdc42-interacting protein 4) restrains synaptic growth by inhibiting the secretion of the retrograde Glass bottom boat signal. J Neurosci 30:8138-8150. CrossRef Medline

Nicholson L, Singh GK, Osterwalder T, Roman GW, Davis RL, Keshishian H (2008) Spatial and temporal control of gene expression in Drosophila using the inducible GeneSwitch GAL4 system. I. Screen for larval nervous system drivers. Genetics 178:215-234. CrossRef Medline

Osterwalder T, Yoon KS, White BH, Keshishian H (2001) A conditional tissue-specific transgene expression system using inducible GAL4. Proc Natl Acad Sci U S A 98:12596-12601. CrossRef Medline

Owald D, Fouquet W, Schmidt M, Wichmann C, Mertel S, Depner H, Christiansen F, Zube C, Quentin C, Körner J, Urlaub H, Mechtler K, Sigrist SJ (2010) A Syd-1 homologue regulates pre- and postsynaptic maturation in Drosophila. J Cell Biol 188:565-579. CrossRef Medline

Pawson C, Eaton BA, Davis GW (2008) Formin-dependent synaptic growth: evidence that Dlar signals via Diaphanous to modulate synaptic actin and dynamic pioneer microtubules. J Neurosci 28:11111-11123. CrossRef Medline

Peng IF, Berke BA, Zhu Y, Lee WH, Chen W, Wu CF (2007) Temperaturedependent developmental plasticity of Drosophila neurons: cellautonomous roles of membrane excitability, $\mathrm{Ca}^{2+}$ influx, and cAMP signaling. J Neurosci 27:12611-12622. CrossRef Medline

Poo MM (2001) Neurotrophins as synaptic modulators. Nat Rev Neurosci 2:24-32. CrossRef Medline

Rawson JM, Lee M, Kennedy EL, Selleck SB (2003) Drosophila neuromuscular synapse assembly and function require the TGF- $\beta$ type I receptor saxophone and the transcription factor Mad. J Neurobiol 55:134-150. CrossRef Medline

Ruiz-Cañada C, Budnik V (2006) Introduction on the use of the Drosophila embryonic/larval neuromuscular junction as a model system to study synapse development and function, and a brief summary of pathfinding and target recognition. Int Rev Neurobiol 75:1-31. CrossRef Medline

Sanyal S, Sandstrom DJ, Hoeffer CA, Ramaswami M (2002) AP-1 functions upstream of CREB to control synaptic plasticity in Drosophila. Nature 416:870 - 874. CrossRef Medline

Sanyal S, Narayanan R, Consoulas C, Ramaswami M (2003) Evidence for cell autonomous AP1 function in regulation of Drosophila motor-neuron plasticity. BMC Neurosci 4:20. CrossRef Medline

Schuster CM, Davis GW, Fetter RD, Goodman CS (1996a) Genetic dissection of structural and functional components of synaptic plasticity: II. Fasciclin II controls presynaptic structural plasticity. Neuron 17:655667. CrossRef Medline

Schuster CM, Davis GW, Fetter RD, Goodman CS (1996b) Genetic dissection of structural and functional components of synaptic plasticity: I. Fasciclin II controls synaptic stabilization and growth. Neuron 17:641654. CrossRef Medline

Shayan AJ, Atwood HL (2000) Synaptic ultrastructure in nerve terminals of Drosophila larvae overexpressing the learning gene dunce. J Neurobiol 43:89-97. CrossRef Medline

Sigrist SJ, Reiff DF, Thiel PR, Steinert JR, Schuster CM (2003) Experiencedependent strengthening of Drosophila neuromuscular junctions. J Neurosci 23:6546-6556. Medline

Smith RB, Machamer JB, Kim NC, Hays TS, Marqués G (2012) Relay of retrograde synaptogenic signals through axonal transport of BMP receptors. J Cell Sci 125:3752-3764. CrossRef Medline

Takaesu NT, Herbig E, Zhitomersky D, O'Connor MB, Newfeld SJ (2005) DNA-binding domain mutations in SMAD genes yield dominantnegative proteins or a neomorphic protein that can activate WG target genes in Drosophila. Development 132:4883-4894. CrossRef Medline

Van Vactor D, Wall DP, Johnson KG (2006) Heparan sulfate proteoglycans and the emergence of neuronal connectivity. Curr Opin Neurobiol 16: 40-51. CrossRef Medline

Wagh DA, Rasse TM, Asan E, Hofbauer A, Schwenkert I, Dürrbeck H, Buchner S, Dabauvalle MC, Schmidt M, Qin G, Wichmann C, Kittel R, Sigrist SJ, Buchner E (2006) Bruchpilot, a protein with homology to ELKS/ CAST, is required for structural integrity and function of synaptic active zones in Drosophila. Neuron 49:833-844. CrossRef Medline

Wang X, Shaw WR, Tsang HT, Reid E, O'Kane CJ (2007) Drosophila spichthyin inhibits BMP signaling and regulates synaptic growth and axonal microtubules. Nat Neurosci 10:177-185. CrossRef Medline

Wills Z, Marr L, Zinn K, Goodman CS, Van Vactor D (1999) Profilin and the Abl tyrosine kinase are required for motor axon outgrowth in the Drosophila embryo. Neuron 22:291-299. CrossRef Medline

Xiao L, Michalski N, Kronander E, Gjoni E, Genoud C, Knott G, Schneggenburger R (2013) BMP signaling specifies the development of a large and fast CNS synapse. Nat Neurosci 16:856-864. CrossRef Medline

Zhang D, Mehler MF, Song Q, Kessler JA (1998) Development of bone morphogenetic protein receptors in the nervous system and possible roles in regulating trkC expression. J Neurosci 18:3314-3326. Medline

Zhong Y, Wu CF (2004) Neuronal activity and adenylyl cyclase in environment-dependent plasticity of axonal outgrowth in Drosophila. J Neurosci 24:1439-1445. CrossRef Medline

Zhong Y, Budnik V, Wu CF (1992) Synaptic plasticity in Drosophila memory and hyperexcitable mutants: role of cAMP cascade. J Neurosci 12 : 644-651. Medline

Zito K, Parnas D, Fetter RD, Isacoff EY, Goodman CS (1999) Watching a synapse grow: noninvasive confocal imaging of synaptic growth in Drosophila. Neuron 22:719-729. CrossRef Medline 